\title{
Never Too Late to Plan: "Refocus on Planning" as an Effective Way to Lower Symptoms and Difficulties in Emotion Regulation During the COVID-19 First Lockdown
}

\author{
Livia Sacchi and Elise Dan-Glauser \\ Institute of Psychology, University of Lausanne
}

\begin{abstract}
Lockdowns during the COVID-19 pandemic have put people in stressful situations. Recent research showed elevated levels of anxiety and depression during this period, but no study has so far evaluated to what extent emotions and regulation difficulties were perceived by people as having changed with the lockdown. This was the major aim of the present study, together with investigating whether the emotion regulation strategy of "Refocus on planning" could be an effective strategy in this context. With a 1 time-point online survey, 635 French-, Italian-, and English- speaking participants (57.6\% males, mean age of 48.48 years, $S D=15.7$ ) evaluated (a) emotion changes, (b) anxiety, depression, and difficulties in emotion regulation, and (c) use of planning. Participants retrospectively indicated their state when thinking about the period of the Spring 2020 COVID-19 lockdown, as well as their state when thinking about the period just before. Results show that the lockdown period was associated with a perceived increase in negative and positive feelings, as well as a perceived increase in anxiety, depression, and regulation difficulties. Despite people used less planning during the lockdown, absolute and heightened use of planning was associated with more positive emotions, as well as less negative emotions, depression symptoms and difficulties in emotion regulation, whereas anxiety symptoms were lower only when more planning was adopted. This study suggests that planning is an effective emotion regulation strategy. More importantly, planning works as soon as implemented, suggesting it is never too late to start planning to alleviate emotion-related symptoms and difficulties.
\end{abstract}

Keywords: COVID-19, emotion-related symptoms, emotion regulation, emotion regulation difficulties, refocus on planning effectiveness

Supplemental materials: https://doi.org/10.1037/emo0001039.supp

Early 2020 European and American countries became gently accustomed to COVID-19 news coming from Asia. But nothing prepared us for the lockdown that occurred within a few weeks around mid-March 2020. Within each country, and often in a few hours, people went from busy working days around coworkers, happy-hour in local bars, getaway with friends and family, to a "stay-home" order by authorities. The consequences of the pandemic and lockdowns on physical health and regional economies are evident. But psychological consequences are also of great importance and need to be characterized.

This article was published Online First November 8, 2021.

Livia Sacchi (D) https://orcid.org/0000-0002-6428-3789

Elise Dan-Glauser (D) https://orcid.org/0000-0002-1715-4650

The authors declare having no conflict of interest. This research was financed by the Swiss National Science Foundation (Grant PCEFP1_ 186836 to Elise Dan-Glauser).

Data are available on the Open-Science Framework platform: https://osf io/8yqtx/.

Correspondence concerning this article should be addressed to Elise DanGlauser, Institute of Psychology, University of Lausanne, Géopolis BuildingUnil Mouline, 1015 Lausanne, Switzerland. Email: elise.danglauser@gmail.com

\section{Difficulties During Life-Threatening Events}

When personal wellbeing and survival is endangered, emotions are among one of the first reactions to take place. Emotions are defined as rapid episodes involving several coordinated responses, like expression or physiological arousal (Gross \& Barrett, 2011; Levenson, 2014; Mauss et al., 2005; Panksepp, 1994; Scherer, 2005), which emerge following a situation that is evaluated as relevant by the individual (Ellsworth \& Scherer, 2003; Moors et al., 2013; Smith \& Ellsworth, 1985).

Complex emotions, such as denial, despair and hopelessness, and emotion-related symptoms, such as depression and anxiety, have been consistently reported in the literature among people witnessing or surviving extremely negative, and possibly traumatic, events (Bodecka et al., 2021; Hammen, 2005; Makwana, 2019; North \& Pfefferbaum, 2013). For example, compared to nonaffected individuals, elevated rates of psychological distress, depression and posttraumatic stress disorder (PTSD) are commonly present in individuals affected directly or indirectly by natural disasters, such as floods and earthquakes (Beaglehole et al., 2018), men-made disasters, such as Chernobyl or Fukushima explosions (Bromet, 2014; Bromet et al., 2011; Shigemura et al., 2021), and by terrorist attacks, such as the 9/11 (Henriksen et al., 2010; Neria 
et al., 2008), as well as the Bataclan and Charlie Hebdo attacks in Paris (Goodwin et al., 2017; Motreff et al., 2020). Of particular relevance to the current study, similar psychological and emotional distress is reported following infectious disease outbreaks, such as the 2003 severe acute respiratory syndrome-SARS (Mak et al., 2009; Yip et al., 2010), the 2009 "Swine flu" (Goodwin et al., 2011; Jones \& Salathé, 2009; Wheaton et al., 2012), and Ebola outbreak of 2013-2016 in Central and West African countries (Ji et al., 2017; Mohammed et al., 2015; Van Bortel et al., 2016).

\section{Difficulties During the COVID-19 Lockdown}

Given the evidence brought so far, and given the similarity of the current pandemic to other life-threatening events, the presence of emotional distress in people with experiences of COVID-19 is not surprising (Gallagher et al., 2020). For example, regarding affects, a surge in negative emotions was observed, notably on social media platforms. Lwin et al. (2020) analyzed worldwide Twitter posts between January and April 2020 and noticed dynamic changes in emotions. Indeed, fear was predominant at the very beginning of the pandemic, but steadily dropped afterward, while anger steadily grew throughout the months. Interestingly, the emotion of sadness stayed constantly low over the months. Similarly, Li and colleagues (2020) investigated the effects of official COVID-19 declarations on emotional reactions, through the study of almost 18'000 active users of one of the principal Chinese online social networks. After the main official declaration about COVID-19 on January 20, 2020; the online use of words related to negative and anxiety-related emotions, such as "worry," "nervous," and "upset," significantly increased. Results from surveys in the general population regarding affects are similar. A Turkish sample mentioned for example that, during the first COVID-19 lockdown, the predominant emotion felt was "worry" (Akdeniz et al., 2020), whereas in Iran, "anxiety" was the most felt affect when informed about COVID-19 by medias (Hamidein et al., 2020). Interestingly, a study among a Polish population showed that, in the first week of the COVID-19 Spring lockdown, the most frequent negative emotions were anger, anxiety and sadness (Moroń \& Biolik-Moroń, 2021). Not all negative emotions showed a change following COVID-19, however. For example, two longitudinal studies on American (Luchetti et al., 2020) and British (O'Connor et al., 2020) samples found no significant change in the levels of perceived loneliness during the early phases of the pandemic.

Counterintuitive results were also found for positive emotions. In the study by Moron and Biolik-Moron (2021), for example, negative emotion frequency was outgrown by happiness report. These results align with many others. Indeed, there was also a steady increase in the use of words related to positive emotions ("faith," "blessing") in the study by $\mathrm{Li}$ et al. (2020), similar to the tweet trends reported by Lwin et al. (2020). These reports of happiness could be explained by feelings of community unity and cohesiveness happening in the context of perceived communal concerns, which foster positive emotions of gratitude and hope (Li et al., 2020; Lwin et al., 2020), and increase perceived support (Luchetti et al., 2020). An alternative explanation could be that governmental measures inducing significant changes in individuals' habits may have laid the seed for more positive situation encountering and consequently increased positive emotions.

Regarding anxiety and depression symptoms, a study in Kuwait shows prevalence of anxiety as high as $25.28 \%$ and the overall prevalence of depressive symptoms as $30.13 \%$ during the pandemic (Burhamah et al., 2020). An Argentinian study shows approximately the same prevalence: $31.8 \%$ for anxiety and $27.5 \%$ for depression (Fernández et al., 2020). Many others studies around the world show similar data (Huang et al., 2020; Hyland et al., 2020; Kujawa et al., 2020; McCracken et al., 2020; Peng et al., 2020; Petzold et al., 2020; Rodríguez-Hidalgo et al., 2020; Shevlin et al., 2020; Smith et al., 2020) and statistics are particularly high in countries strongly or suddenly hit by the pandemic like the United States (Liu et al., 2020; Rudenstine et al., 2020), China (Tang et al., 2020), or Spain (Planchuelo-Gómez et al., 2020). These data focus on symptoms during the pandemic, but one can wonder whether the prevalence was similar before the pandemic or whether it evolved with the lockdowns. A particularly relevant study on this aspect focused on French students during the first COVID-19 lockdown, and asked them to evaluate how their anxiety evolved from before to during the lockdown (Husky et al., 2020). Nearly two-third of the sample $(60.2 \%)$ reported that their anxiety level had increased since the beginning of the lockdown. Hence, the burden of the COVID-19 restrictions and fear appears to be high on mental health, but few studies show to what extent it was perceived to have changed.

Given the extreme burden the pandemic has shown to have on mental health, and given the prevalence of negative emotions and emotion-related symptoms, many authors and professionals stress the importance of emotion regulation skills (Fernández et al., 2020; Sweeney, 2020; Xiong et al., 2020), suggesting for patients to adopt cognitive reappraisal (i.e., reevaluating the emotion triggering situation) or acceptance (de Siqueira Rotenberg et al. 2020). However, little is truly known about emotion regulation difficulties and their perceived change in the time of COVID-19 lockdown.

\section{Emotion Regulation Strategies and Difficulties}

Emotion regulation refers to the processes by which people modulate their emotional emergence and responses (Gross, 1998) Whereas effective emotion regulation plays a crucial role in wellbeing, healthy adaptation to the environment (Gross \& John, 2003; Gross \& Muñoz, 1995), and efficient social functioning (Eisenberg et al., 2000), difficulties in emotion regulation are particularly associated with anxiety and mood disorders (Campbell-Sills \& Barlow, 2007; Mennin et al., 2002, 2005; Tull \& Roemer, 2007). Evaluating the levels of difficulties in emotion regulation is thus extremely important in a context where anxiety and depression are prone to be magnified.

As a specific subset of emotion regulation strategies, cognitive emotion regulation strategies focus on how environmental cues are processed at the central level and, in turn, how this processing either triggers or modifies desired (or undesired) emotions (McRae, 2016). Given the wide connection of these cognitive strategies with anxiety and depressive symptoms (Bruggink et al., 2016; Domaradzka \& Fajkowska, 2018), investigation of cognitive emotion regulation strategies is an interesting avenue to identify current and prospective (potentially more effective) emotion regulation patterns 
regarding symptoms. Based on their taxonomy of cognitive regulation strategies, Garnefski et al. (2001) developed the Cognitive Emotion Regulation Questionnaire (CERQ). This instrument evaluates to what extent nine different cognitive strategies - classified as adaptive and maladaptive - can be used in daily life to face demanding situations. The adaptive-maladaptive classification was proposed since many studies showed that symptoms (such as depressive and anxiety ones) were systematically associated to a specific set of strategies, such as self-blame, rumination and catastrophizing (Garnefski \& Kraaij, 2007).

Among the strategies proposed within this taxonomy, "Refocus on planning" (or focusing on planning) and its effect on emotions remain understudied. "Refocus on planning" refers to "Thinking about what steps to take and how to handle the negative event. It is the cognitive part of action-focused coping, which does not automatically imply that actual behavior will follow" (Garnefski et al., 2001; p. 1315). Planning is a problemfocused strategy in itself (Carver et al., 1989) and an important component of problem solving (Naragon-Gainey et al., 2017). It entails the action of breaking the problem down into different aspects and define an order to address them (Gick, 1986). Planning indirectly impacts the emotion emergence process and therefore could also function as an emotion regulation strategy. Despite it has been considered as an adaptive strategy (Garnefski et al., 2001), its benefits have not been clearly demonstrated. Indeed, while some analyses failed to highlight any relationship with anxiety or depressive symptoms (Garnefski et al., 2002), others have nevertheless observed a negative association of this strategy use with the occurrence of certain kind of depressive symptoms (Domaradzka \& Fajkowska, 2018), particularly in nonclinical samples (Lei et al., 2014). It has also been found to be negatively associated with anxiety (Min et al., 2013), as well as with worry (Zlomke \& Hahn, 2010).

Particular contexts may be a determinant factor in the use and effectiveness of emotion regulation strategies (Aldao, 2013; Aldao \& Nolen-Hoeksema, 2012; Dixon-Gordon et al., 2015). Better understanding how specific situations impact emotion regulation strategies is pivotal in the process of developing and refining the tools available to aid emotion regulation in future similar situations. In the context of the current pandemic, while one study shows a relatively strong association between the use of adaptive emotion regulation strategies as defined by Garnefski and well-being during the lockdown period (Gubler et al., 2020), another one shows a prevalent use of problem-focused regulation and distraction during the COVID-19 period (Hamidein et al., 2020). Muñoz-Navarro et al. (2021) addressed the mediating role of emotion regulation strategies between COVID-related worry and anxiety symptoms. Results showed that adaptive emotion regulation strategies had a direct effect on decreasing anxiety, while maladaptive emotion regulation strategies mediated the relationship between COVID-related worry and anxiety symptoms, with a general worsening of mental health. Of note, scores of the single strategies were pooled together and the single contribution of each strategy is unknown. If so-called adaptive emotion regulation strategies are also considered by other authors to buffer the negative impact of the pandemic on health-related anxiety (Jungmann \& Witthöft, 2020), suppression could heighten it (Trougakos et al., 2020). Of particular relevance to the current study, Zacher and Rudolph (2021) longitudinally investigated the changes in subjective well-being from December 2019 to May 2020 in a German community sample as predicted by the fourteen coping strategies of the COPE inventory (Carver et al., 1989). In a model considering all these strategies together, planning was associated with lower levels of life satisfaction, and no association was found with positive and negative affect.

So far, very few data are thus available regarding emotion regulation in times of COVID-19, and even less on the singular effect of planning. More importantly, relationship of planning use with symptoms and regulation difficulties in times of COVID-19 is so far unknown. The lockdown procedure forced a significant proportion of people to face new challenges and adjustments in their daily life (Brooks et al., 2020; Matias et al., 2020). To face these situations, we believe that a strategy that includes environmental organization such as planning could have simultaneously promoted the regulation of negative emotions and the reduction of distress symptoms triggered by the pandemic and the confinement. In other words, planning could have actually served as a protective factor for mental health.

\section{The Present Research}

In the present study, we used a cross-sectional survey in French-, Italian- and English-speaking European populations with the general aim of investigating the changes in emotions, symptoms, and difficulties in emotion regulation, as retrospectively perceived by individuals from before to during the lockdown. Despite some limitations, retrospective ratings had the merit to obtain information about previous symptoms (see, e.g., Husky et al., 2020), information we could not gather in advance due to the intrinsic unforeseeable feature of the pandemic. In addition, with this study, we aimed at uncovering how the use of planning could coincide with a regulation of these symptoms and the modulation of regulation difficulties.

We had five specific objectives. We wanted to investigate (a) the perceived change of the frequency of negative and positive emotions, calculated as a difference between people retrospective evaluations of how they felt before and during the first COVID-19 lockdown; (b) the perceived level and changes of several emotion-related symptoms (anxiety and depression), as well as of emotion regulation difficulties within the same periods; (c) the perceived frequency of use of the strategy of planning, as remembered from before and during the lockdown; and (d) the impact of the use of the strategy of planning during the lockdown on perceived changes in emotions, as well as symptoms and difficulties. Since daily activities, working duties, and social interactions have been totally disrupted by the sudden lockdown, people may have considered using other strategies than usual, and increased their use of planning. Following this assumption, we also wanted to investigate whether a sudden increase in the use of planning at the time of the lockdown (even if not used previously) had an impact on the perceived emotions, symptoms, and difficulty changes (e). For each of these five aims, we had the following hypotheses:

H1: the negative emotion levels will be reported as having increased during the first COVID-19 lockdown (Spring 2020). Conversely, the positive emotion levels will be reported as 
having decreased during the lockdown as compared to its retrospectively estimated prepandemic levels ${ }^{1}$.

H2: anxiety and depressive symptoms, as well as perceived difficulties in emotion regulation, will be reported as having been higher during the first COVID-19 lockdown (Spring 2020) as compared to their retrospectively estimated prepandemic levels.

H3: the use of the strategy of planning will be reported as having been higher during the first COVID-19 lockdown (Spring 2020) as compared to its retrospectively estimated prepandemic use level.

H4: the use of the strategy of planning should coexist with lower perceived symptoms of anxiety, depression, and difficulties in emotion regulation.

H5: an estimated higher use of the strategy of planning during the lockdown, as compared to before, should be associated with less perceived worsening of symptoms and regulation difficulties.

\section{Method}

\section{Participants}

The sample size needed was of $N=550$ and was calculated with a power analysis (with GPower 3.1) for regressions (increase in $R^{2}, 10$ models) with each time 6 independent variables (five controls and one predictor), for an alpha of .05 , a power of .80 , and a $f^{2}=.15$. At the end of the recoding period, 635 participants had completed the survey. Of these, 260 $(40.9 \%)$ were female and $366(57.6 \%)$ were males (with 9 people not reporting gender, $1.5 \%$ ). Fifty-four percent of the participants were between 46 and 65 years old. Taking the center of the measured age categories as a reference, our sample had a mean age of 48.48 years $(S D=15.7)$. Table 1 below shows a detailed description of the sample. Our typical participant is a man, living in Italy and speaking Italian, married or in partnership, having higher education and performing nearly all their professional duties remotely during the lockdown.

\section{Measures}

Three versions of the survey were created: one in English, one in French, and one in Italian. When available, the validated version of the original English questionnaires translated into French and Italian was used. In the remaining case (detailed here-below), translations were performed by the authors.

\section{Demographic, Geographical-Linguistic, and Occupational Variables}

Ten questions were asked to investigate participant individual variables. Demographic variables were Gender (3 answer categories: "Male," "Female," "Do not wish to answer"), Age (14 categories from less than 20 years old to above 85 years old in fiveyear increments and a "Do not wish to answer" option), and Marital Status (6 options: "Single,"“Married," "Registered partnership," "Divorced," "Widowed," and "Do not wish to answer"). Due to the number of responses received, Age was later grouped into six categories of mainly 10-year increments; Marital Status labeled Married and Registered partnership were also later grouped (See Table 1). Regarding languages and localization of respondents, Native Language and Country of Residence were asked as open questions and later grouped into four main categories each (see Table 1). Education had four possible answer options (see Table 1) with an additional "Do not wish to answer" option. Activity during the lockdown was evaluated with a six-option choice answering the question: "During the COVID lockdown period, did you work from home?" Answers, designed to provide indications about the amount of duties that were remotely performed, were later grouped into four categories (see Table 1). There were then questions on the main Occupation, Contract Percentage, and Household Composition, which were not used in the analyses.

\section{Emotion Changes}

In order to evaluate the emotional change concomitant to the first COVID lockdown (Spring 2020), we used a modified version of the Positive and Negative Affect Schedule (PANAS) scale. In its original form, the PANAS scale comprises 20 items (10 positive and 10 negative items), each presenting an emotional label such as "Excited," "Distressed," "Proud," or "Afraid." The labels are rated according to the frequency of the felt emotions during a given period, for example "in the last few weeks" or "in the last few days" (Watson et al., 1988). In order to reduce the length of the survey, and since we were interested in the perceived change of emotions from before to during the lockdown, our participants had to answer to the question "Please indicate whether you experienced the following emotions more or less frequently than before the lockdown:" on a 5 level Likert scale going from "A lot less than before," later recoded as -2 , to "A lot more than before," later recorded as +2 . Responses were later averaged across the 10 items of the respective valence to form a negative emotion change score and a positive emotion change score (each ranging from -2 to +2 Reliability analyses for the negative and positive scales were very satisfactory, Cronbach's s $\alpha$ reaching .86 for the negative scales (.86-.90 in the original version) and .84 for the positive scale (.84-.87 in the original version).

\section{Anxiety and Depression Symptoms}

To examine anxiety and depression symptoms, we used the 7item Generalized Anxiety Disorder Scale - GAD-7 (Löwe et al., 2008; Spitzer et al., 2006) and the 2-item Patient Health Questionnaire - PHQ-2 (Kroenke et al., 2003; Löwe et al., 2005), respectively, which have shown good validity and reliability. French and Italian versions were made available by the original authors of the screens (https://www.phqscreeners.com/). Participants had to indicate the frequency at which they were bothered by anxious and depressive symptoms for a given period on a 4 level Likert scale from "Not at all" (later coded 0) to "Nearly every day" (later coded 3. Sum of scores were then calculated, ranging from 0 to 21 for anxiety and from 0 to 6 for depression. These questionnaires were filled twice during the same session: first, we asked participants to fill the questionnaire while thinking about the period

\footnotetext{
${ }^{1}$ This hypothesis was set before the publication of the many results showing the opposite, and was thus kept as such in the present report.
} 
Table 1

Sample Descriptives on Demographic, Geographical, Linguistic, and Occupational Variables

\begin{tabular}{|c|c|c|c|c|}
\hline Characteristics & Categories & $N$ & $\%$ & $\chi^{2}$ goodness of fit \\
\hline \multirow[t]{3}{*}{ Gender } & Male & 366 & $57.6 \%$ & \multirow{9}{*}{$\chi_{(1, \mathrm{~N}=626)}^{2}=17.9, p<.001$} \\
\hline & Female & 260 & $40.9 \%$ & \\
\hline & & & & \\
\hline \multirow{7}{*}{ Age (years) } & $18-25$ & 78 & $12.3 \%$ & \\
\hline & $26-35$ & 98 & $15.5 \%$ & \\
\hline & $36-45$ & 47 & $7.4 \%$ & \\
\hline & $46-55$ & 142 & $22.4 \%$ & \\
\hline & $56-65$ & 198 & $31.2 \%$ & \\
\hline & $>65$ & 71 & $11.2 \%$ & \\
\hline & & & & \multirow{4}{*}{$\chi_{(5, \mathrm{~N}=634)}^{2}=145, p<.001$} \\
\hline \multirow[t]{4}{*}{ Survey language } & Italian & 423 & $66.6 \%$ & \\
\hline & French & 142 & $22.4 \%$ & \\
\hline & English & 70 & $11.0 \%$ & \\
\hline & & & & \multirow{3}{*}{$\chi_{(2, \mathrm{~N}=635)}^{2}=329, p<.001$} \\
\hline \multirow[t]{2}{*}{ Survey filled in } & Native language & 565 & $89.0 \%$ & \\
\hline & Foreign language & 70 & $11.0 \%$ & \\
\hline \multirow{6}{*}{ Marital status } & & & & \multirow{5}{*}{$\chi_{(1, \mathrm{~N}=635)}^{2}=386, p<.001$} \\
\hline & Single & 157 & $24.7 \%$ & \\
\hline & Married/Partnership & 408 & $64.3 \%$ & \\
\hline & Divorced & 36 & $5.7 \%$ & \\
\hline & Widowed & 14 & $2.2 \%$ & \\
\hline & & & & \multirow{5}{*}{$\chi_{(3, \mathrm{~N}=615)}^{2}=638, p<.001$} \\
\hline \multirow[t]{5}{*}{ Country of residence } & Italy & 397 & $62.5 \%$ & \\
\hline & Switzerland & 157 & $24.7 \%$ & \\
\hline & France & 55 & $8.7 \%$ & \\
\hline & Other & 25 & $3.9 \%$ & \\
\hline & & & & \multirow[t]{5}{*}{$\chi_{(3, \mathrm{~N}=634)}^{2}=539, p<.001$} \\
\hline \multirow[t]{5}{*}{ Education } & Primary & 3 & $0.5 \%$ & \\
\hline & High School & 39 & $6.1 \%$ & \\
\hline & Higher vocational education & 61 & $9.6 \%$ & \\
\hline & College or university & 525 & $82.7 \%$ & \\
\hline & & & & \multirow[t]{5}{*}{$\chi_{(3, \mathrm{~N}=628)}^{2}=1,161, p<.001$} \\
\hline \multirow[t]{5}{*}{ Language } & Italian & 431 & $67.9 \%$ & \\
\hline & French & 138 & $21.7 \%$ & \\
\hline & English & 18 & $2.8 \%$ & \\
\hline & Other & 48 & $7.6 \%$ & \\
\hline & & & & \multirow[t]{5}{*}{$\chi_{(3, \mathrm{~N}=635)}^{2}=672, p<.001$} \\
\hline \multirow{5}{*}{ Activity during lockdown } & $100 \%$ remote & 339 & $53.4 \%$ & \\
\hline & $50 \%$ remote & 61 & $16.7 \%$ & \\
\hline & Minimal or no remote work & 104 & $28.5 \%$ & \\
\hline & On site & 31 & $4.9 \%$ & \\
\hline & & & & $\chi_{(3, \mathrm{~N}=535)}^{2}=440, p<.001$ \\
\hline
\end{tabular}

during the Spring 2020 lockdown (mid-March to mid-May 2020) and, second, while thinking about the period spanning two months before the Spring 2020 lockdown (mid-January to mid-March 2020). GAD-7 in our full sample indicated a very good reliability: Cronbach's $\mathrm{s} \alpha=.89$ for the questionnaire filled in relationship to during the lockdown and Cronbach's s $\alpha=.90$ for the questionnaire filled in relationship to before the lockdown. Comparison between GAD-7 language versions showed that alphas for the three versions were not significantly different, $\chi_{(2, \mathrm{~N}=70,142,423)}^{2}=$ $4.37, p=.113$ for the lockdown period and $\chi_{(2, \mathrm{~N}=70,142,423)}^{2}=2.41$, $p=.300$ for the period before (Diedenhofen \& Musch, 2016). PHQ-2 in our sample indicated a reduced but still fair reliability: Cronbach's s $\alpha=.74$ for the questionnaire filled about the lockdown period and Cronbach's s $\alpha=.76$ for the questionnaire filled while thinking about the period before the lockdown. Comparison between PHQ-2 language versions showed that alphas for the three versions were not significantly different, $\chi_{(2, \mathrm{~N}=70,142,423)}^{2}=3.97$, $p=.137$ for the lockdown period and $\chi_{(2, \mathrm{~N}=70,142,423)}^{2}=4.28, p=$ .118 for the period before (Diedenhofen \& Musch, 2016).

\section{Difficulties in Emotion Regulation}

The Difficulties in Emotion Regulation Scale (Short Form, DERS-SF) was used to measure difficulties in emotion regulation. This instrument includes 18 items representing six factors of emotion regulation difficulties (Gratz \& Roemer, 2004; Kaufman et al., 2016). In order to reduce the survey duration, only nine items were taken from this instrument, which corresponded to the three subscales correlating the most with the total score (Goals, Impulse, and Strategy subscales, see Hallion et al., 2018). Corresponding items were taken in the validated French and Italian versions of the DERS (Dan-Glauser \& Scherer, 2013; Sighinolfi et al., 2010). For each faced difficulty in emotion regulation described in the items, participants had to indicate how often they reacted that way, ranging from "Almost never" (later recoded as 1) to "Almost 
always" (later recoded as 5). Again, these nine items were filled twice during the same session: first, while thinking about the period during the Spring 2020 lockdown (mid-March to mid-May 2020) and, second, while thinking about the period spanning two months before the Spring 2020 lockdown (mid-January to midMarch 2020). Reliability of this reduced questionnaire was quite high, Cronbach's s $\alpha$ reaching .92 for the questionnaire filled when thinking about the period during the lockdown, and .90 for the questionnaire filled when thinking about the period before the lockdown. Comparison between DERS-9 item language versions showed that alphas for the three versions were not significantly different, $\chi_{(2, \mathrm{~N}=70,142,423)}^{2}=3.24, p=.198$ for during the lockdown, but was significant $\chi_{(2, \mathrm{~N}=70,142,423)}^{2}=10.93, p=.004$ for the period before the lockdown (Diedenhofen \& Musch, 2016), indicating that especially the English version (Cronbach's s $\alpha=$ .85) was a less reliable version than the one proposed in Italian (Cronbach's s $\alpha=.92), \chi_{(1, \mathrm{~N}=70,423)}^{2}=10.78, p=.001$. The difficulties in emotion regulation were subsequently analyzed as a single metrics averaging the scores on the nine items.

\section{Planning}

Only few (sub)scales evaluate planning. Since no work has specifically contrasted them, we decided to use the three of them. One subscale that is specifically dedicated to refocus on planning in its regulatory definition is the subscale "Refocus on Planning" from the CERQ (Garnefski et al., 2001), also used in Muñoz-Navarro et al. (2021). In the Coping Orientation to Problems Experienced, the COPE (Carver et al., 1989), there is a subscale called "Planning," with a similar definition to the Garnefski's subscale (see Introduction section. For the French and Italian versions of the survey, we used either the corresponding validated translations (Jermann et al., 2006; Muller \& Spitz, 2003; Sica et al., 1997) or translated ourselves the remaining items (two items not present in the briefCOPE, both in French and Italian, and the four items of the CERQ in Italian. In addition, the Planfulness scale (Ludwig et al., 2018) was used as a state-measure form of planning. As this scale was not available in French nor in Italian, it was translated by the authors. Examples of items are "I develop a clear plan when I have a goal" and "I think about specific ways that I can achieve my goals." All items were then grouped under the same questionnaire, and participants were asked to analyze the behavior related to the management of difficult situations with the following instruction: "Think about the period during/before the lockdown, and about the strategy you used to reduce negative emotions, how frequently did you ... ." All items were scored from "Almost never" (later coded as 1) to "Almost always" (later coded as 5 Average scores were calculated after reversing 2 items. These 14 items were filled twice during the same session: first, while thinking about the period during the Spring 2020 lockdown (mid-March to mid-May 2020) and, second, while thinking about the period spanning two months before the Spring 2020 lockdown (mid-January to mid-March 2020). Reliability analyses retrospectively revealed two problematic items within these 14 aggregated items (two items from the Planfulness scale); they were thus removed from the scale. Next, we investigated if we should include the three scores (of the three instruments) separately in the analyses or consider them together as one unique measure of planning. The 12 items together reached an excellent reliability: Cronbach's $\mathrm{s} \alpha=.94$ for the questionnaire filled about the lockdown period and Cronbach's s $\alpha=.96$ for the questionnaire filled when retrospectively thinking about the period before the lockdown. These values were higher than any of the $\alpha$ measured for single questionnaires ( $\alpha$ ranging from .85 and .94). Intercorrelations between scores of the three instruments were also very high (ranging from .61 to .83 , all $p<.001)$. In addition, analyses of intraclass correlation coefficients resulted in an ICC of $.87, F(634,1268)=7.39$, $p<.001,95 \%$ CI $[.85, .88]$ for the measure "during," while the measure "before" resulted in an ICC of $.91, F(634,1268)=10.91$, $p<.001,95 \%$ CI $[.90, .92]$. These results represent good and excellent reliability, respectively. Thus, when looking at the perspective of finding a unique instrument for planning, we opted for grouping the three scales. Moreover, an exploratory factor analysis (principal axis) suggested that this instrument represents one single factor (principal axis extraction, scree test criterion), explaining $56.8 \%$ of the variance for planning during and $66.3 \%$ for planning before the lockdown. Comparison between the Planning questionnaire language versions showed that alphas for the three versions were not significantly different, $\chi_{(2, \mathrm{~N}=70,142,423)}^{2}=0, p=$ 1 for the lockdown period and $\chi_{(2, \mathrm{~N}=70,142,423)}^{2}=1.78, p=.41$ for the period before (Diedenhofen \& Musch, 2016).

\section{Other Measures}

We tested the remaining four items of the Planfulness scale that were strongly related to trait-planfulness (Ludwig et al., 2018). This trait-planning subscale did not indicate good reliability and was therefore not analyzed further (Cronbach's s $\alpha=.42$ ). These four items were (in the survey) aggregated with a measure of personality, the 10 item Big-Five inventory - BFI (Rammstedt et al., 2013), which were included to gather pilot data for another study and were not considered further for the present investigation.

\section{Recruitment and Procedure}

Data were collected from May 15th to August 10th, 2020, with each participant filling the questionnaire only once. Participants were recruited through advertisements on the authors' LinkedIn and Facebook pages, through WhatsApp groups and professional mailing lists. Survey sharing was highly encouraged. Participants were not rewarded for this study. After joining the survey page on a Google Form, participants were provided with the information about the study, that is, the purpose, the duration, and the anonymization statement, and then had to click on "Agree to participate" to give informed consent to be enrolled in the study. No specific identifiers (such as name or address) were requested to participate. The only inclusion criteria were to be older than 18 years old and speak the language of the questionnaire relatively fluently. Participants then filled the questionnaires in a given order, starting with the BFI and trait-planfulness, followed by the PANAS and the section specific to the first COVID-19 lockdown, with a targeted period going from mid-March to mid-May 2020. In this section, participants filled the GAD7 and PHQ-2, the partial DERS, as well as the planning questionnaire. Participants then moved to the next section, examining the period preceding the COVID-19 lockdown, period that we specified spanned between mid-January to mid-March 2020. They filled again the GAD7, PHQ-2, DERS and planning questionnaire while referring to this particular period. Participants were then taken to the last section where they entered 
their gender, age, marital status, language, residence, household composition, education, profession, and contract type. In addition, they answered to a specific question about their activity during the lockdown. The last screen encouraged people with difficulties facing lockdown consequences or any worry related to the situation to contact local hotlines. Moreover, a contact name was given to receive more information or ask questions about the study. Participants could then leave the survey after being thanked for their participation. All the procedure lasted 10-15 minutes. The protocol was approved by our institutional ethic committee ("Commission Ethique de la Recherche de l'Université de Lausanne," CER-Unil, SSP), with the identification number: C_SSP_112020_00006.

\section{Data Analyses}

\section{Preliminary Data Checks}

Exploration of demographic data were performed with $\chi^{2}$ to check repartition into the different levels of the categorical variables (see Table 1). Cronbach's s $\alpha$ were used to check the reliability of the questionnaire used. Differences between Cronbach's $\alpha$ s for the different language version were also tested with $\chi^{2}$. All these preliminary checks are reported in the method section.

\section{Perceived Changes of Emotions During the Lockdown}

Evaluation of perceived changes in affective states from before to after the lockdown was made with Student $t$-tests as compared to a 0 -centered distribution.

\section{Perceived Symptom and Difficulty Changes}

The perceived changes in symptoms (anxiety and depression) and difficulties in emotion regulation were evaluated with a unique score. It permitted to avoid including time as an additional factor in our subsequent regression analyses (see below) and retain sufficient power for highlighting significant differences. Perceived change scores of symptoms and difficulties were calculated as follows: score during - score before the lockdown. This index was analyzed by calculating Student $t$-tests as compared to a 0 -centered distribution.

\section{Perceived Planning Use Changes}

Similarly, the perceived change in planning use was evaluated with a unique score. Perceived change of planning use scores were calculated as follows: score during - score before the lockdown. This index was analyzed by calculating Student t-tests as compared to a 0 -centered distribution.

\section{The Relationship Between the Use of and Changes in Planning, Emotions, and Symptoms}

Our targeted research questions (i.e., if the emotion regulation strategy of planning affected emotions and symptoms, and their perceived changes) were evaluated by performing two regression analyses for each outcome (positive emotion, negative emotion, anxiety level, depression level, difficulties in emotion regulation). The first regression looked at the impact of the level of absolute perceived planning use during the lockdown on perceived emotion changes and absolute perceived levels of symptoms, and difficulties during the same period. The second regression evaluated if perceived changes in planning use in difficult time predicted perceived changes in emotions, symptoms, and difficulties in emotion regulation. All models were stepwise regression models controlling for age, gender, marital status, residence, and language in a first step.

Analyses were performed with SPSS (IBM SPSS Statistics for Windows, Version 25.0. Armonk, NY: IBM Corp.) and Jamovi (Version 1.2.27, retrieved from www.jamovi.org). No correction for multiple comparisons were performed due to the objective of not decreasing type I error to the detriment of type II error (Althouse, 2016; Perneger, 1998; Rothman, 1990). Regression prerequisite checks showed that no transformation was necessary for our dataset and nontransformed variables were used in all analyses.

Since the impact of demographic and geographical characteristics on symptoms and use of planning is well-established (Elezi et al., 2020; Huang \& Zhao, 2020; Martin \& Dahlen, 2005; Min et al., 2013; Moghanibashi-Mansourieh, 2020; Picaza Gorrochategi et al., 2020; Saravanan et al., 2020; Smith et al., 2020), these controls are investigated in separate analyses and reported in a Supplementary Result File (File S1).

\section{Results}

\section{Perceived Changes of Emotions During the Lockdown}

Not surprisingly, during the lockdown period, the perceived frequency of negative feelings was reported to have significantly increased, $M=0.15, S D=0.58, t(634)=6.38, p<.001, d=.25$. Interestingly, for the lockdown period, the perceived frequency of positive feelings was also reported to have increased, $M=0.10$, $S D=0.60, t(634)=4.16, p<.001, d=.17$. Detailed reports of the specific emotion categories can be found in Figure S1).

\section{Perceived Symptom and Difficulty Changes}

\section{Anxiety}

When thinking about the period before the lockdown, participants reported an average level of anxiety of $4.24(20.2 \%, S D=$ 3.86 , range $0-21$ ). When thinking about the lockdown period, the average level of anxiety was at $4.94(23.5 \%, S D=4.26$, range $=$ $0-21$ ). The increase in perceived anxiety symptoms (averaging $3.3 \%$ ) was significant $t(634)=4.22, p<.001, d=.17$.

\section{Depression}

When thinking about the period before the lockdown, participants reported an average level of depression of .91 $(15.2 \%, S D=$ 1.22 , range $0-6)$. When thinking about the lockdown period, the average level of depression was at $1.33(22.2 \%, S D=1.38$, range $=$ $0-6$ ). The increase in perceived depression symptoms (averaging $7 \%$ ) was significant $t(634)=7.8, p<.001, d=.31$.

\section{Emotion Regulation Difficulties}

When thinking about the period before the lockdown, participants reported an average level of difficulties in emotion regulation of $1.36(27.2 \%, S D=0.48$, range $1-5)$. When thinking about the lockdown period, the average level of difficulties was at 1.54 $(30.8 \%, S D=0.68$, range $=1-4.67)$. The increase in emotion 
regulation difficulties (averaging 3.6\%) was significant $t(634)=$ $7.34, p<.001, d=.29$.

\section{Perceived Changes in Planning Use}

When thinking about the period before the lockdown, participants reported an average use of the emotion regulation strategy of planning of $3.36(67.2 \%, S D=0.98$, range $1-5)$. When thinking about the lockdown period, the average use of this strategy was $1.18(23.6 \%, S D=0.95$, range $=1.08-5)$. The decrease in the use of planning (averaging 43.6\%) was significant $t(634)=6.09, p<$ $.001, d=.24$.

\section{The Relationship Between the Use of and Changes in Planning, Emotions, and Symptoms}

\section{Relationship to Emotions}

Negative Emotion. Regression analyses showed that planning during the lockdown was a significant predictor of the perceived changes in negative emotions, $R^{2}=.05, F(1,633)=32.1, p<$ $.001, \mathrm{~b}=-0.13,95 \% \mathrm{CI}[-.18,-.09]$. This was true even when controlling for age, gender, marital status, residence, and native language in a first model, $\Delta R^{2}=.05, F(1,591)=29.4, p<.001$. Hardly using planning is associated with an increase of negative emotions by .44 points $(+22 \%)$, while extensively using planning is associated with a reduction of negative emotions by 0.1 points $(-5 \%)$. This result is shown in Figure 1A. A second regression with the change in the perceived use of planning from before to during the lockdown showed also a significant prediction of the perceived change in negative emotions, $R^{2}=.01, F(1,633)=7.94$, $p=.005, \mathrm{~b}=-0.09,95 \% \mathrm{CI}[-.15,-.03]$. This was true even when controlling for age, gender, marital status, residence and native language in a first model, $\Delta R^{2}=.01, F(1,591)=8.98, p=$ .003. Not changing the use of planning was linked to perceived increase in negative emotions of 0.13 points $(+7 \%)$, while perceived increase in the use of planning by 1.48 point was associated with no perceived changes in negative emotions following the lockdown. This result is shown in Figure 1B.

Positive Emotions. Regression analyses showed that planning during the lockdown was a significant predictor of the perceived changes in positive emotions, $R^{2}=.14, F(1,633)=106, p<.001$, $\mathrm{b}=0.24,95 \%$ CI $[.19, .28]$. This was true even when controlling for age, gender, marital status, residence, and native language in a first model, $\Delta R^{2}=.13, F(1,591)=98.5, p<.001$. Hardly using planning is associated with a perceived decrease in positive emotions by 0.42 points $(-21 \%)$ while extensively using planning was associated with a perceived increase in positive emotions by 0.53 points $(+26 \%)$. This result is shown in Figure 1C. A second regression with the retrospectively perceived change in the use of focusing on planning from before to during the lockdown showed also a significant prediction of the perceived change in positive emotions, $R^{2}=.07, F(1,633)=45.7, p<.001, \mathrm{~b}=0.21,95 \% \mathrm{CI}$ $[.15, .27]$. This was true even when controlling for age, gender, marital status, residence and native language in a first model, $\Delta R^{2}=$ $.06, F(1,591)=40.7, p<.001$. Perceived unchanged use of the strategy of planning was associated with a perceived increase in positive emotions of 0.14 points $(+7 \%)$, while maximally changing the use of planning (going from 1 to 5 on the use scale) could be paired with a perceived increase in positive emotions of 0.98 points $(+49 \%)$. This result is shown in Figure 1D.

\section{Relationship to Symptoms}

Anxiety. Regression analyses showed that planning during the lockdown was a significant predictor of anxiety levels, $R^{2}=$ $.009, F(1,633)=5.89, p=.016, \mathrm{~b}=-0.43,95 \%$ CI $[-.78$, $-.08]$. This was however not valid anymore when controlling for age, gender, marital status, residence, and native language in a first model, $\Delta R^{2}=.003, F(1,591)=1.88, p=.17$. A second regression with the perceived change in the use of focusing on planning from before to during the lockdown showed also a significant prediction of the perceived change in anxiety level, $R^{2}=$ $.01, F(1,633)=7.96, p=.005, \mathrm{~b}=-0.64,95 \%$ CI $[-1.08$, $-.19]$. This was still true even when controlling for age, gender, marital status, residence and native language in a first model, $\Delta R^{2}=.02, F(1,591)=11.7, p<.001$. Perceived unchanged use of the strategy of planning was associated with a perceived increase in anxiety level of 0.58 points $(+3 \%)$ while maximally increasing the use of planning ( +4 points) is associated with a decrease of anxiety level following the lockdown by 1.96 points $(-9 \%)$. This result is shown in Figure 2.

Depression. Regression analyses showed that planning during the lockdown was a significant predictor of depression levels, $R^{2}=.06, F(1,633)=41.6, p<.001, \mathrm{~b}=-0.36,95 \%$ CI $[-.47$, $-.25]$. This was true even when controlling for age, gender, marital status, residence, and native language in a first model, $\Delta R^{2}=$ $.03, F(1,591)=22.2, p<.001$. Hardly using planning is associated with a depression level of 2.11 points (35\%), while extensively using planning is associated with lower depression levels at 0.67 points $(11 \%)$. This result is shown in Figure 3A. A second regression with the perceived change in the use of focusing on planning from before to during the lockdown showed also a significant prediction of the perceived change in depression level, $R^{2}=.02, F(1,633)=15.9, p<.001, \mathrm{~b}=-0.29,95 \% \mathrm{CI}$ $[-.43,-.15]$. This was true even when controlling for age, gender, marital status, residence, and native language in a first model, $\Delta R^{2}=.02, F(1,591)=15.3, p<.001$. Perceived unchanged use of planning was linked to a perceived increase in depressive symptoms of $0.36(+6 \%)$, while maximally increasing the use of planning $(+4$ points) could be paired with a perceived decrease the depression level following the lockdown by 0.78 points $(-13 \%)$. This result is shown in Figure 3B.

\section{Difficulties in Emotion Regulation}

Regression analyses showed that planning during the lockdown was a significant predictor of the perceived levels of emotion regulation difficulties, $R^{2}=.04, F(1,633)=28.2, p<.001, \mathrm{~b}=-0.15$, $95 \%$ CI $[-.20,-.09]$. This was true even when controlling for age, gender, marital status, residence and native language in a first model, $\Delta R^{2}=.02, F(1,591)=15.2, p<.001$. Hardly using planning predicts difficulties of emotion regulation equal to 1.86 points $(21 \%)$, while extensively using it predicts lower perceived levels of difficulties in emotion regulation at 1.27 points (7\%). This result is shown in Figure 4A. A second regression with the retrospectively perceived change in the use of planning from before to during the lockdown also significantly predicted the perceived change in the level of emotion regulation difficulties, 
Figure 1

Perceived Changes in Negative (A and B) and Positive (C and D) Emotions From Before to During the March-May 2020 Lockdown According to the Perceived Absolute Use of Planning ( $A$ and $C$ ) or the Perceived Changes in Planning Use (B and D)

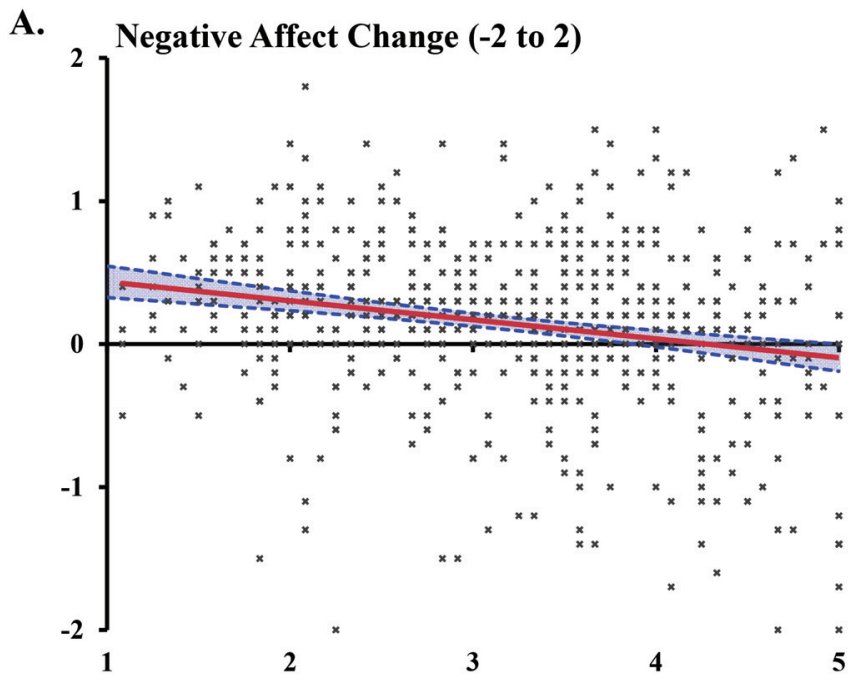

B. Negative Affect Change (-2 to 2)

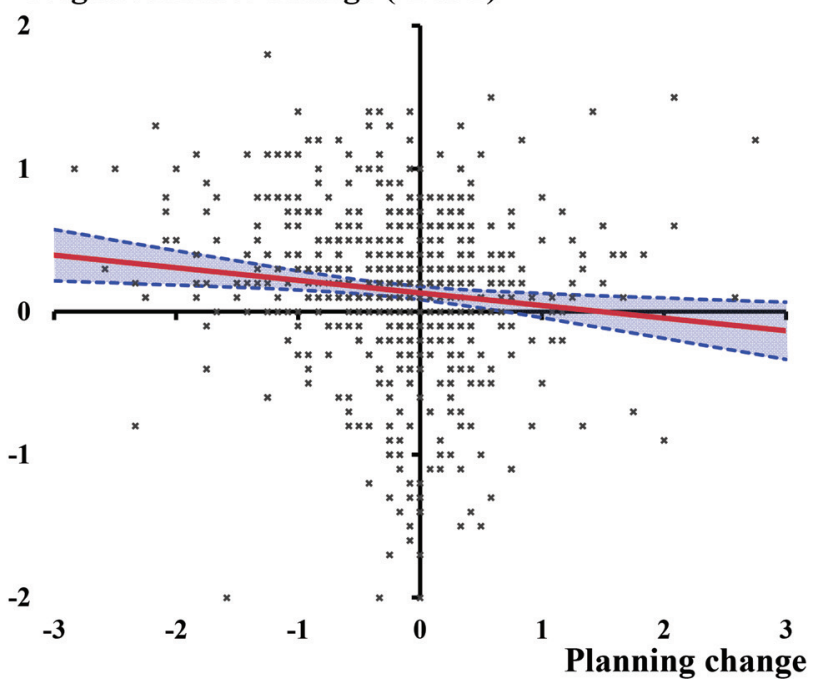

C.

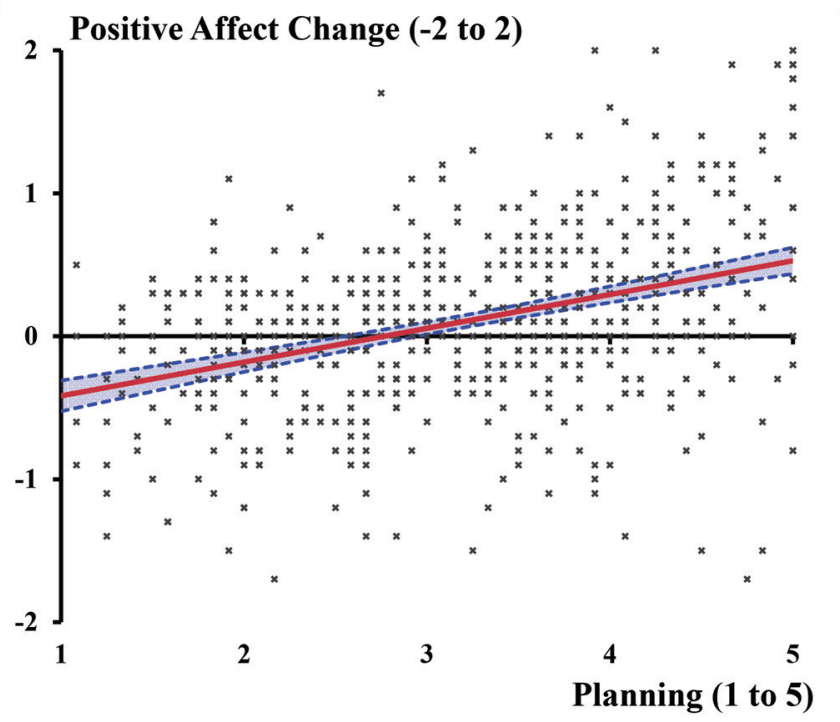

D.

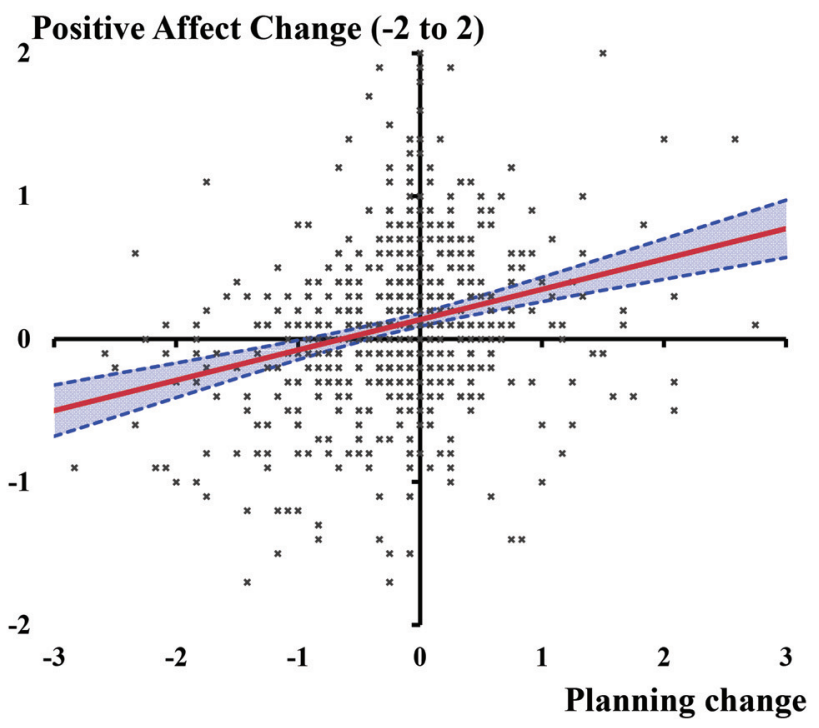

Note. Participants are identified with crosses (multiple participants may be overlaid on a single cross). Linear regression lines are displayed in red. Blue dotted lines represent confidence interval (95\%) of the regression lines. See the online article for the color version of this figure.

$R^{2}=.03, F(1,633)=19.3, p<.001, \mathrm{~b}=-0.14,95 \% \mathrm{CI}[-.21$, $-.08]$. This was true even when controlling for age, gender, marital status, residence, and native language in a first model, $\Delta R^{2}=$ $.03, F(1,591)=18.6, p<.001$. Perceived unchanged use of the strategy of planning was linked to a perceived increase in the emotion regulation difficulties of 0.15 points $(+4 \%)$, while maximally increasing the use of planning $(+4$ points) could be associated with a decrease in the perceived level of emotion regulation difficulties following the lockdown by 0.42 points $(-11 \%)$. A change in planning of only 1.06 points already permitted to remain at a constant level of difficulties from before to during the lockdown. This result is shown in Figure 4B.

\section{Discussion}

Beyond the medical challenge of the current COVID-19 pandemic, illness fear and the consequences of the government protection measures took a toll on people's mental functioning. The first general aim of this study was to investigate the perceived levels, and, more importantly, the changes in perceived levels of emotion occurrence and emotion-related symptoms and difficulties. One important aspect in our study was hence to include measures of the perception of changes that occurred from before the pandemic to during the Spring 2020 lockdown. The second main goal was to examine the relationship of perceived emotion change and 
Figure 2

Perceived Changes in Anxiety Symptoms From Before to During the March-May 2020 Lockdown According to the Changes in Planning Use

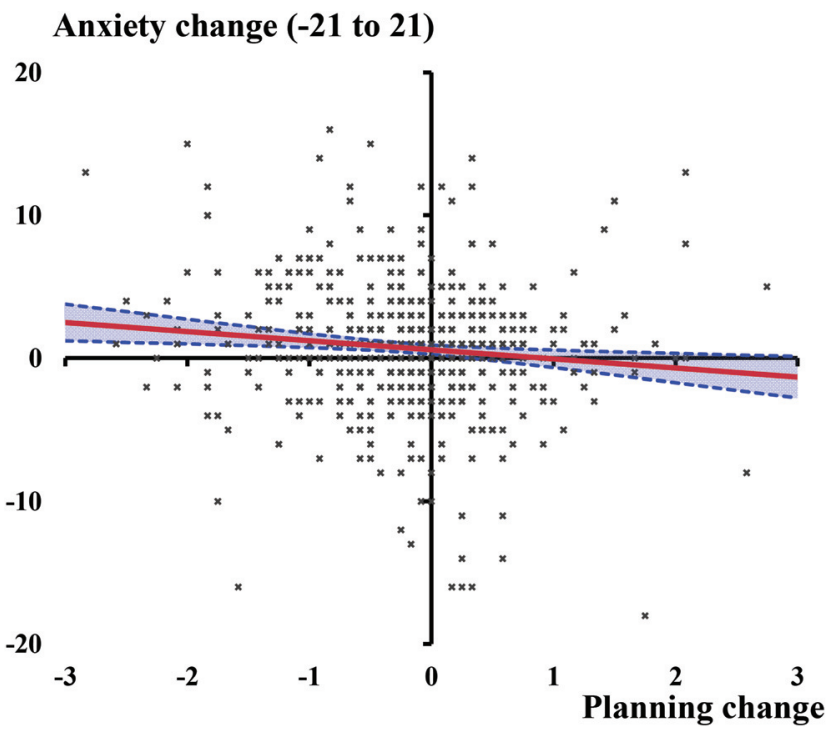

Note. Participants are identified with crosses (multiple participants may be overlaid on a single cross). Linear regression line is displayed in red. Blue dotted lines represent confidence interval (95\%) of the regression line. See the online article for the color version of this figure.

emotion related symptoms with the use of a particularly understudied emotion regulation strategy: "Refocus on planning." We thought that it was a particularly well-suited strategy to face the lockdown organizational challenges and that it could, in parallel, reduce negative emotion occurrence and relieve symptoms. We thus aimed to determine if, and to what extent, planning was an effective emotion regulation strategy. We also evaluated the impact of the perceived change in planning use. In particular, we wondered whether intensifying planning use is beneficial. This latter question is notably important to determine if the planning strategy can be recommended unreservedly in case of major crisis.

Our one-time point survey was conducted in three different languages, mostly intended to be filled by Switzerland and Italy residents, but which eventually also included France residents. We expected to see a perceived increase in negative emotions, anxiety and depressive symptoms, and difficulties in emotion regulation from before to during the Spring 2020 COVID-19 lockdown, as retrospectively evaluated at one time-point by the participants. We also hypothesized that the lockdown would have spurred an increase in the use of the strategy of planning, and that its use would have coexisted with lower symptoms of anxiety, depression, and lower difficulties in emotion regulation. Finally, we aimed to show that a perceived increase in the use of the strategy of planning was significantly associated with lower perceived worsening of symptoms and regulation difficulties from before to after the lockdown. Our hypotheses were overall confirmed. We found an increase in perceived negative feelings, but also, interestingly, an increase in perceived positive feelings. Anxiety levels, depression and emotion regulation difficulty levels were also reported as having increased significantly. Contrary to expectation, people reported overall to have decreased their use of planning during the lockdown. However, use and increased use of planning was associated with decreases in negative emotions, depression symptoms and difficulties in emotion regulation, as well as with an increase in positive emotions. Anxiety symptoms were not associated with the overall level of planning, yet they still diminished when more planning was adopted during the lockdown. We discuss below three major (or most intriguing) findings about the COVID-19 lockdown impact on emotion and emotion-related symptoms and difficulties, including what the planning results tell us about the possible benefits of this particular emotion regulation strategy.

First, we want to discuss the higher frequency level of positive emotions reported during this difficult time. This finding is particularly intriguing since such situations are believed to trigger mostly negative emotions. However, positive and negative emotions often coexist in difficult times (Folkman \& Moskowitz, 2000) and the presence of positive emotions is considered essential for coping and resilience (Fredrickson et al., 2003; Tugade et al., 2004). In the case of the COVID-19 pandemic, a diary study on a Polish sample reported a lot of happiness during the pandemic period (Moroń \& Biolik-Moron, 2021), which is congruent with our findings. Interestingly, a study on character strengths found also that intellectual strengths (i.e., open-mindedness, creativity, curiosity and love of learning) were more conducive to overall personal resilience during the pandemic, including positive mental health, life satisfaction and positive affect (Martínez-Martí et al., 2020). Such character strength could have been particularly present in our sample, which includes a majority of highly educated individuals who generally possess such characteristics, thus explaining the positive affect finding.

The second point of our discussion deals with the symptoms and changes of symptoms as retrospectively reported by the participants. We also want to relate this to age impact and the gender effect we found on anxiety measures (see Supplementary Result File S1). First of all, the reported level of anxiety and depression were similar to those observed in other studies (see, e.g., Asmundson et al., 2020). Furthermore, we found similar results concerning age as other COVID-19 studies, which showed that younger individuals were more affected by the pandemic than older individuals (Elezi et al., 2020; Huang \& Zhao, 2020; Moghanibashi-Mansourieh, 2020; Picaza Gorrochategi et al., 2020; Saravanan et al., 2020; Smith et al., 2020). An interesting finding of our study regards the fact that, whereas anxiety levels were retrospectively reported to have increased in men from before to during the pandemic, this is not the case for women, who did not report a perceived significant increase in their anxiety level. This is in contradiction with some evidence generally showing less favorable anxiety levels after a major life event for women than for men (Bergerot et al., 2017; Russell et al., 2008). Of course, events described in these studies (chemotherapy and transplantation, respectively) are far more intense than a lockdown, which could explain the difference. Moreover, the current pandemic situation may not have been perceived to be as stressful for women as it has been for men. This may be related to occupational differences and the changes that were induced in the daily activities, which may not have been as drastic for women as it has been for men.

Third, we want to highlight some aspects of our results regarding the use of planning and its importance in, directly or indirectly, modulating emotions and emotion-related difficulties. First of all, 
Figure 3

Perceived Depression Symptom Level During the March-May 2020 Lockdown According to the Perceived Use of Planning (A) and Perceived Changes in Depression Symptoms From Before to During The Lockdown According to the Changes in Planning Use From Before to During The Lockdown (B)
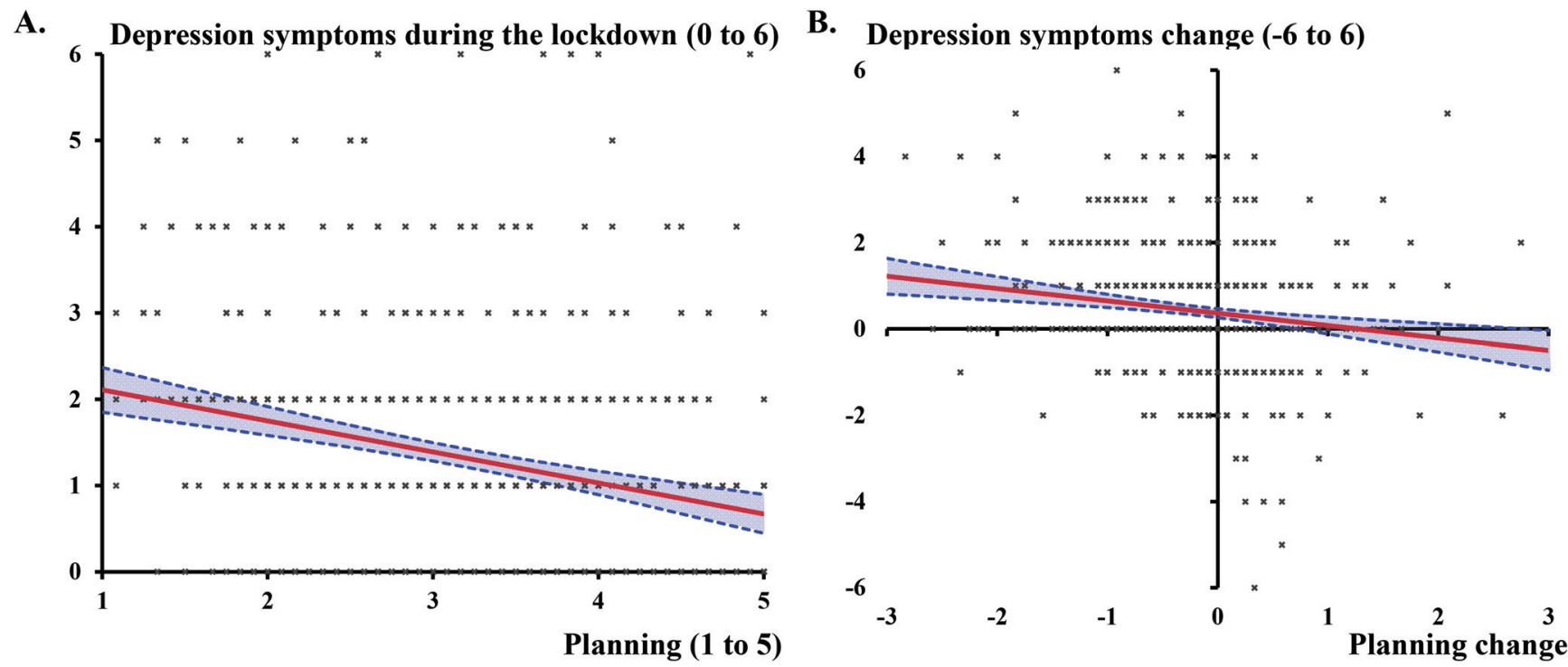

Note. Participants are identified with crosses (multiple participants may be overlaid on a single cross). Linear regression lines are displayed in red. Blue dotted lines represent confidence interval (95\%) of the regression lines. See the online article for the color version of this figure.

our hypothesis about the increased use of planning was not confirmed. A potential explanation could be that our sample may not have had much more problems that needed planning with the lockdown, but rather a reduction of tasks, and therefore a less urgent or frequent need to plan. It could be also that the specific planning we evaluated here (that is intended as working toward a specific goal with division of the problem into subsets, the finding of a solution and defining a strategy with incremental steps) was not the

Figure 4

Perceived Difficulties in Emotion Regulation Level During the March-May 2020 Lockdown According to the Perceived Use of Planning (A) and Changes in Difficulties in Emotion Regulation Level From Before to During the Lockdown According the Perceived Changes in Planning Use From Before to During The Lockdown (B)

A.

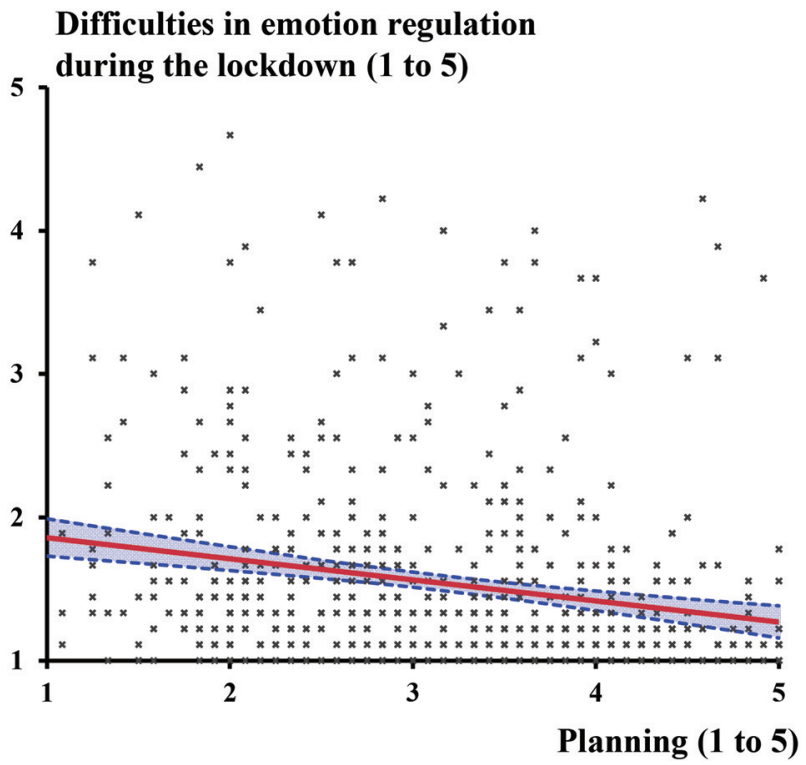

B. Difficulties in emotion regulation change (-4 to 4$)$

4

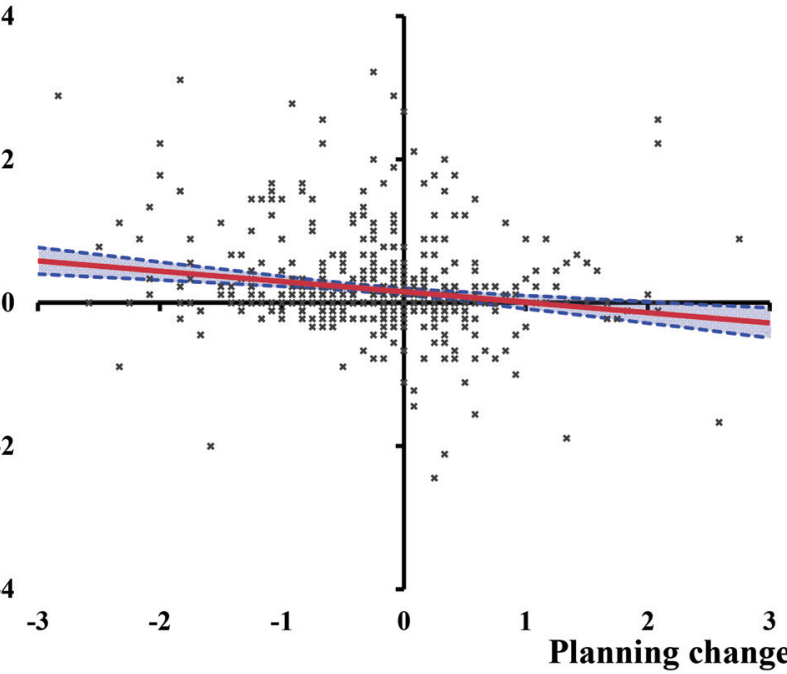

Note. Participants are identified with crosses (multiple participants may be overlaid on a single cross). Linear regression lines are displayed in red. Blue dotted lines represent confidence interval (95\%) of the regression lines. See the online article for the color version of this figure. 
most performed strategy at this stage of the pandemic. Given the fact that our survey was conducted in the early phases of the outbreak (March 2020-August 2020), participants might have had difficulties in identifying problems and setting clear goals. Nevertheless, we confirmed one of our major hypotheses by showing systematic associations between the use of planning and a reduction in the retrospectively reported levels of negative emotions, depressive symptoms and emotion regulation difficulties. These results are in contrast with the ones of Zacher and Rudolph (2021). However, we think that their considering of fourteen strategies in a unique model, particularly by also including highly functioning strategies such as active coping, may have blunted the results of maybe less impacting, but nevertheless important, strategies such as planning. In any case, at this stage, the direction of a potential causal effect linking planning to the reported emotional relief is unknown. On the one hand, fewer difficulties could potentially make the individuals more prone to use planning by freeing up cognitive resources needed to do so (what we could call resource model). On the other hand, planning may be an effective strategy causing an actual reduction in the emotional burden (what we could call effective strategy model). Given the results highlighting the perceived changes in symptoms from before to during the lockdown as compared to the perceived change in the use of planning, we tend to favor the second model. Indeed, we can see that the general increase of symptoms is not associated with a less frequent use of planning, as it would be the case if the resource model was into play. On the contrary, we see very clearly that starting to use planning once the lockdown has been commanded is associated with less negative emotions, decrease of symptoms and difficulties, and a quite important perceived increase in positive emotions. Two conclusions can be drawn from these results. First, using "Refocus on planning" as a regulation strategy could also be a way to successfully regulate emotions in daily activities. This implies however to be very cautious about the way it is implemented. One optimal way would be to consider daily challenges as obstacles to reach a goal. Clearly defining the goal would be crucial as a first step of this implementation. However, a foreseeable downside related to this strategy could be the spiraling into obsessive planning, which, eventually, could lead to less beneficial outcomes, such as stress or procrastination. Second, based on our results, this strategy does not appear to be difficult to implement (or to increase its use), nor to necessitate a phase of adaptation for the positive effects to take place. Hence, we could recommend "Refocus on planning" as an effective strategy, to be implemented daily to regulate emotion, but also in particular time where the frequency of stressful situations increases, such as in times of pandemic.

\section{Limitations and Future Directions}

Several limitations can be pointed out regarding this study. The first limitation relates to the convenience of the sample recruited. We cannot rule out the possibility of incurring an important selfselection bias in our sample. In other words, participation might have been endorsed by participants with specific characteristics (such as people being more depressed, anxious, or lonely, for example). The second limitation, which is closely linked to the first, regards the nature of the sample recruited. Despite having sufficient participants for testing our hypotheses, we had a rather small sample with respect to the intended target population. Several reasons concurred to this limitation. The data gathering was restricted to two months in order not to let the imprecision of the individuals' evaluations grow (particularly with respect to the period starting mid-January 2020). Moreover, our link sharing did not work as well as expected: overrepresentation of certain class of people is evident, which limits the generalizability of our findings. In addition, since we did not want to burden our participants with a lengthy survey, we had to be selective in our demographics choice, leading to a clear omission of some information that could have helped us refining our results, such as the respondent ethnicity, for example. In parallel to this point, we found many differences in our variables that were mitigated by the residence of the participants. Even more importantly, we lacked a detailed knowledge about the measures that these participants were under (such as whether they were on full or partial lockdown), as well as the real contact they had with the COVID-19 illness, to fully explore the impact of such differences within each country. The third limitation has to do with the lack of validated translations of many instruments. Despite extensive work on the translation and very satisfactory internal consistency, we lacked external validations for some instruments. It would be worth in future studies to obtain fully validated scales and questionnaires for these topics in different languages. This would increase the potential gathering of data across non-English-speaking countries and a more global understanding of the mechanisms of emotion and emotion regulation that occur in these populations. Our fourth limitation related to the use of self-reported and retrospective evaluations of symptoms and difficulties. People had to rely on their memory of their health state several months before the lockdown and with such an intense period in between, we could wonder if recall is accurate. Despite this, demographic and geographical parameters modulate the results and show for certain subgroups a nonevolution of symptoms or difficulties (see Supplementary Result File S1), which speaks against a general bias of worsening of symptom report. Finally, since this was the first study on planning effect on emotional symptoms, we took several related methodological choices (such as one common conception of planning and no correction for multiple comparisons) that should be dealt with in future replications of this study. Related to this, it would have been interesting to focus on other types of strategies to make a comparison. This represents a clearly interesting future direction.

\section{Conclusions}

To our knowledge, this study is the first to investigate the retrospective self-perception of the impact of the COVID-19 Spring 2020 lockdown on emotion frequency, emotion-related symptoms, and difficulties in managing emotions. Moreover, rare are the studies on the regulation strategy of "Refocus on planning"; a strategy that we show here to be reliably associated with less reported symptomatology and emotion-related difficulties. Within the same sample, our design allowed us not only to evaluate the retrospectively perceived evolution of symptoms and difficulties from before to during the lockdown, but also to investigate the use of planning and its associated effects. We found that the lockdown impacted the emotions and emotion related symptoms and highlighted that, despite the situation, people could also find occasions to feel positive emotions. Interestingly, planning seems to be an 
useful strategy to, maybe indirectly, decrease negative emotions, increase positive emotions, as well as reduce depression and regulation difficulties. Furthermore, it appears to be a strategy that is easy to implement, with immediate effects on symptomatology. In conclusion, our study highlights that planning should be considered as a potentially effective strategy for regulating emotions and that it could well be recommended to deal with stressful and negative situations, probably even beyond the COVID-19 crisis.

\section{References}

Akdeniz, G., Kavakci, M., Gozugok, M., Yalcinkaya, S., Kucukay, A., \& Sahutogullari, B. (2020). A survey of attitudes, anxiety status, and protective behaviors of the university students during the COVID-19 outbreak in Turkey. Frontiers in Psychiatry, 11, 695. https://doi.org/10 $.3389 /$ fpsyt.2020.00695

Aldao, A. (2013). The future of emotion regulation research: capturing context. Perspectives on Psychological Science, 8(2), 155-172. https:// doi.org/10.1177/1745691612459518

Aldao, A., \& Nolen-Hoeksema, S. (2012). The influence of context on the implementation of adaptive emotion regulation strategies. Behaviour Research and Therapy, 50(7-8), 493-501. https://doi.org/10.1016/j.brat .2012 .04 .004

Althouse, A. D. (2016). Adjust for multiple comparisons? It's not that simple. The Annals of Thoracic Surgery, 101(5), 1644-1645. https://doi .org/10.1016/j.athoracsur.2015.11.024

Asmundson, G. J. G., Paluszek, M. M., Landry, C. A., Rachor, G. S., McKay, D., \& Taylor, S. (2020). Do pre-existing anxiety-related and mood disorders differentially impact COVID-19 stress responses and coping? Journal of Anxiety Disorders, 74, 102271. https://doi.org/10 $.1016 /$ j.janxdis.2020.102271

Beaglehole, B., Mulder, R. T., Frampton, C. M., Boden, J. M., NewtonHowes, G., \& Bell, C. J. (2018). Psychological distress and psychiatric disorder after natural disasters: Systematic review and meta-analysis. The British Journal of Psychiatry, 213(6), 716-722. https://doi.org/10 $.1192 /$ bjp. 2018.210

Bergerot, C. D., Mitchell, H. R., Ashing, K. T., \& Kim, Y. (2017). A prospective study of changes in anxiety, depression, and problems in living during chemotherapy treatments: Effects of age and gender. Supportive Care in Cancer, 25(6), 1897-1904. https://doi.org/10.1007/s00520-017 $-3596-9$

Bodecka, M., Nowakowska, I., Zajenkowska, A., Rajchert, J., Kaźmierczak, I., \& Jelonkiewicz, I. (2021). Gender as a moderator between present-hedonistic time perspective and depressive symptoms or stress during COVID-19 lock-down. Personality and Individual Differences, 168, 110395. https://doi.org/10.1016/j.paid.2020.110395

Bromet, E. J. (2014). Emotional consequences of nuclear power plant disasters. Health Physics, 106(2), 206-210. https://doi.org/10.1097/HP .000000000000012

Bromet, E. J., Havenaar, J. M., \& Guey, L. T. (2011). A 25 year retrospective review of the psychological consequences of the Chernobyl accident. Clinical Oncology, 23(4), 297-305. https://doi.org/10.1016/j.clon .2011 .01 .501

Brooks, S. K., Webster, R. K., Smith, L. E., Woodland, L., Wessely, S., Greenberg, N., \& Rubin, G. J. (2020). The psychological impact of quarantine and how to reduce it: Rapid review of the evidence. Lancet, 395(10227), 912-920. https://doi.org/10.1016/S0140-6736(20)30460-8

Bruggink, A., Huisman, S., Vuijk, R., Kraaij, V., \& Garnefski, N. (2016). Cognitive emotion regulation, anxiety and depression in adults with autism spectrum disorder. Research in Autism Spectrum Disorders, 22, 34-44. https://doi.org/10.1016/j.rasd.2015.11.003

Burhamah, W., AlKhayyat, A., Oroszlanyova, M., AlKenane, A., Almansouri, A., Behbehani, M., Karimi, N., Jafar, H., \& AlSuwaidan, M.
(2020). The psychological burden of the COVID-19 pandemic and associated lockdown measures: Experience from 4000 participants. Journal of Affective Disorders, 277, 977-985. https://doi.org/10.1016/j.jad.2020 .09 .014

Campbell-Sills, L., \& Barlow, D. H. (2007). Incorporating emotion regulation into conceptualizations and treatments of anxiety and mood disorders. In J. J. Gross (Ed.), Handbook of emotion regulation (pp. 542-559). Guilford Press.

Carver, C. S., Scheier, M. F., \& Weintraub, J. K. (1989). Assessing coping strategies: A theoretically based approach. Journal of Personality and Social Psychology, 56(2), 267-283. https://doi.org/10.1037/0022-3514 .56.2.267

Dan-Glauser, E. S., \& Scherer, K. R. (2013). The Difficulties in Emotion Regulation Scale (DERS): Factor structure and consistency of a French translation. Swiss Journal of Psychology, 72(1), 5-11. https://doi.org/10 .1024/1421-0185/a000093

de Siqueira Rotenberg, L., Cohab Khafif, T., Nascimento, C., \& Lafer, B. (2020). Emotion regulation and bipolar disorder: Strategies during the COVID-19 pandemic. Bipolar Disorders, 22, 879-882. https://doi.org/ 10.1111/bdi.13001

Diedenhofen, B., \& Musch, J. (2016). cocron: A web interface and R package for the statistical comparison of Cronbach's alpha coefficients. International Journal of Internet Science, 11(1), 51-60.

Dixon-Gordon, K. L., Aldao, A., \& De Los Reyes, A. (2015). Emotion regulation in context: Examining the spontaneous use of strategies across emotional intensity and type of emotion. Personality and Individual Differences, 86, 271-276. https://doi.org/10.1016/j.paid.2015.06.011

Domaradzka, E., \& Fajkowska, M. (2018). Cognitive emotion regulation strategies in anxiety and depression understood as types of personality. Frontiers in Psychology, 9, 856. https://doi.org/10.3389/fpsyg.2018.00856

Eisenberg, N., Fabes, R. A., Guthrie, I. K., \& Reiser, M. (2000). Dispositional emotionality and regulation: Their role in predicting quality of social functioning. Journal of Personality and Social Psychology, 78(1), 136-157. https://doi.org/10.1037/0022-3514.78.1.136

Elezi, F., Tafani, G., Sotiri, E., Agaj, H., \& Kola, K. (2020). Assessment of anxiety and depression symptoms in the Albanian general population during the outbreak of COVID-19 pandemic. Indian Journal of Psychiatry, 62(9, Suppl 3), S470-S475. https://doi.org/10.4103/psychiatry .IndianJPsychiatry_842_20

Ellsworth, P. C., \& Scherer, K. R. (2003). Appraisal processes in emotion. In R. J. Davidson, H. H. Goldsmith, \& K. R. Scherer (Eds.), Handbook of affective sciences (pp. 572-595). Oxford University Press.

Fernández, R. S., Crivelli, L., Guimet, N. M., Allegri, R. F., \& Pedreira, M. E. (2020). Psychological distress associated with COVID-19 quarantine: Latent profile analysis, outcome prediction and mediation analysis. Journal of Affective Disorders, 277, 75-84. https://doi.org/10.1016/j.jad 2020.07.133

Folkman, S., \& Moskowitz, J. T. (2000). Positive affect and the other side of coping. American Psychologist, 55(6), 647-654. https://doi.org/10 .1037/0003-066X.55.6.647

Fredrickson, B. L., Tugade, M. M., Waugh, C. E., \& Larkin, G. R. (2003). What good are positive emotions in crises? A prospective study of resilience and emotions following the terrorist attacks on the United States on September 11th, 2001. Journal of Personality and Social Psychology, 84(2), 365-376. https://doi.org/10.1037/0022-3514.84.2.36

Gallagher, M. W., Zvolensky, M. J., Long, L. J., Rogers, A. H., \& Garey, L. (2020). The impact of Covid-19 experiences and associated stress on anxiety, depression, and functional impairment in American adults. Cog nitive Therapy and Research, 44(6), 1-9. https://doi.org/10.1007/s10608 -020-10143-y

Garnefski, N., \& Kraaij, V. (2007). The cognitive emotion regulation questionnaire: Psychometric features and prospective relationships with depression and anxiety in adults. European Journal of Psychological Assessment, 23(3), 141-149. https://doi.org/10.1027/1015-5759.23.3.141 
Garnefski, N., Kraaij, V., \& Spinhoven, P. (2001). Negative life events, cognitive emotion regulation and emotional problems. Personality and Individual Differences, 30(8), 1311-1327. https://doi.org/10.1016/ S0191-8869(00)00113-6

Garnefski, N., Legerstee, J., Kraaij, V. V., Van Den Kommer, T., \& Teerds, J. (2002, December). Cognitive coping strategies and symptoms of depression and anxiety: A comparison between adolescents and adults. Journal of Adolescence, 25(6), 603-611. https://doi.org/10.1006/ jado.2002.0507

Gick, M. L. (1986). Problem-solving strategies. Educational Psychologist, 21(1-2), 99-120. https://doi.org/10.1080/00461520.1986.9653026

Goodwin, R., Gaines, S. O., Jr., Myers, L., \& Neto, F. (2011). Initial psychological responses to swine flu. International Journal of Behavioral Medicine, 18(2), 88-92. https://doi.org/10.1007/s12529-010 $-9083-z$

Goodwin, R., Kaniasty, K., Sun, S., \& Ben-Ezra, M. (2017). Psychological distress and prejudice following terror attacks in France. Journal of Psychiatric Research, 91, 111-115. https://doi.org/10.1016/j.jpsychires .2017 .03 .001

Gratz, K. L., \& Roemer, L. (2004). Multidimensional assessment of emotion regulation and dysregulation: Development, factor structure, and initial validation of the Difficulties in Emotion Regulation Scale. Journal of Psychopathology and Behavioral Assessment, 26(1), 41-54. https://doi.org/10.1023/B:JOBA.0000007455.08539.94

Gross, J. J. (1998). The emerging field of emotion regulation: An integrative review. Review of General Psychology, 2(3), 271-299. https://doi .org/10.1037/1089-2680.2.3.271

Gross, J. J., \& John, O. P. (2003). Individual differences in two emotion regulation processes: Implications for affect, relationships, and wellbeing. Journal of Personality and Social Psychology, 85(2), 348-362. https://doi.org/10.1037/0022-3514.85.2.348

Gross, J. J., \& Muñoz, R. F. (1995). Emotion regulation and mental health. Clinical Psychology: Science and Practice, 2(2), 151-164. https://doi .org/10.1111/j.1468-2850.1995.tb00036.x

Gross, J. J., \& Barrett, L. F. (2011). Emotion generation and emotion regulation: One or two depends on your point of view. Emotion Review, 3(1), 8-16. https://doi.org/10.1177/1754073910380974

Gubler, D. A., Makowski, L. M., Troche, S. J., \& Schlegel, K. (2020). Loneliness and well-being during the covid-19 pandemic: Associations with personality and emotion regulation. Journal of Happiness Studies, 1-20. https://doi.org/10.1007/s10902-020-00326-5

Hallion, L. S., Steinman, S. A., Tolin, D. F., \& Diefenbach, G. J. (2018). Psychometric properties of the Difficulties in Emotion Regulation Scale (DERS) and its short forms in adults with emotional disorders. Frontiers in Psychology, 9, 539. https://doi.org/10.3389/fpsyg.2018 .00539

Hamidein, Z., Hatami, J., \& Rezapour, T. (2020). How people emotionally respond to the news on COVID-19: An online survey. Basic and Clinical Neuroscience, 11(2), 171-178. https://doi.org/10.32598/bcn.11 .covid19.809.2

Hammen, C. (2005). Stress and depression. Annual Review of Clinical Psychology, 1(1), 293-319. https://doi.org/10.1146/annurev.clinpsy.1.102803 .143938

Henriksen, C. A., Bolton, J. M., \& Sareen, J. (2010). The psychological impact of terrorist attacks: Examining a dose-response relationship between exposure to $9 / 11$ and Axis I mental disorders. Depression and Anxiety, 27(11), 993-1000. https://doi.org/10.1002/da.20742

Huang, Y., \& Zhao, N. (2020). Generalized anxiety disorder, depressive symptoms and sleep quality during COVID-19 outbreak in China: A web-based cross-sectional survey. Psychiatry Research, 288, 112954. https://doi.org/10.1016/j.psychres.2020.112954

Huang, Y. Y., Wang, Y. X., Zeng, L. Y., Yang, J. Z., Song, X. L., Rao, W. W., Li, H. H., Ning, Y. P., He, H. B., Li, T., Wu, K., Chen, F. J., Wu, F. C., \& Zhang, X. Y. (2020). Prevalence and correlation of anxiety, insomnia and somatic symptoms in a chinese population during the covid-19 epidemic. Frontiers in Psychiatry, 11, 568329. https://doi.org/ 10.3389/fpsyt.2020.568329

Husky, M. M., Kovess-Masfety, V., \& Swendsen, J. D. (2020). Stress and anxiety among university students in France during Covid-19 mandatory confinement. Comprehensive Psychiatry, 102, 152191. https://doi.org/ 10.1016/j.comppsych.2020.152191

Hyland, P., Shevlin, M., McBride, O., Murphy, J., Karatzias, T., Bentall, R. P., Martinez, A., \& Vallieres, F. (2020). Anxiety and depression in the Republic of Ireland during the COVID-19 pandemic. Acta Psychiatrica Scandinavica, 142(3), 249-256. https://doi.org/10.1111/acps .13219

Jermann, F., Van der Linden, M., d'Acremont, M., \& Zermatten, A. (2006). Cognitive Emotion Regulation Questionnaire (CERQ): Confirmatory factor analysis and psychometric properties of the French translation. European Journal of Psychological Assessment, 22(2), 126-131. https://doi.org/10.1027/1015-5759.22.2.126

Ji, D., Ji, Y.-J., Duan, X.-Z., Li, W.-G., Sun, Z.-Q., Song, X.-A., Meng, Y.-H., Tang, H.-M., Chu, F., Niu, X.-X., Chen, G.-F., Li, J., \& Duan, H.-J. (2017). Prevalence of psychological symptoms among Ebola survivors and healthcare workers during the 2014-2015 Ebola outbreak in Sierra Leone: A cross-sectional study. Oncotarget, 8(8), 12784-12791. https://doi.org/10.18632/oncotarget.14498

Jones, J. H., \& Salathé, M. (2009). Early assessment of anxiety and behavioral response to novel swine-origin influenza $\mathrm{A}(\mathrm{H} 1 \mathrm{~N} 1)$. PLoS ONE, 4(12), Article e8032. https://doi.org/10.1371/journal.pone.0008032

Jungmann, S. M., \& Witthöft, M. (2020, June). Health anxiety, cyberchondria, and coping in the current COVID-19 pandemic: Which factors are related to coronavirus anxiety? Journal of Anxiety Disorders, 73, 102239. https://doi.org/10.1016/j.janxdis.2020.102239

Kaufman, E. A., Xia, M., Fosco, G., Yaptangco, M., Skidmore, C. R., \& Crowell, S. E. (2016). The Difficulties in Emotion Regulation Scale Short Form (DERS-SF): Validation and replication in adolescent and adult samples. Journal of Psychopathology and Behavioral Assessment, 38(3), 443-455. https://doi.org/10.1007/s10862-015-9529-3

Kroenke, K., Spitzer, R. L., \& Williams, J. B. (2003). The Patient Health Questionnaire-2: Validity of a two-item depression screener. Medical Care, 41(11), 1284-1292. https://doi.org/10.1097/01.MLR.0000093487 $.78664 .3 \mathrm{C}$

Kujawa, A., Green, H., Compas, B. E., Dickey, L., \& Pegg, S. (2020). Exposure to COVID-19 pandemic stress: Associations with depression and anxiety in emerging adults in the United States. Depression and Anxiety, 37, 1280-1288. https://doi.org/10.1002/da.23109

Lei, H., Zhang, X., Cai, L., Wang, Y., Bai, M., \& Zhu, X. (2014). Cognitive emotion regulation strategies in outpatients with major depressive disorder. Psychiatry Research, 218(1-2), 87-92. https://doi.org/10.1016/ j.psychres.2014.04.025

Levenson, R. W. (2014). The autonomic nervous system and emotion. Emotion Review, 6(2), 100-112. https://doi.org/10.1177/17540739 13512003

Li, S., Wang, Y., Xue, J., Zhao, N., \& Zhu, T. (2020). The impact of COVID-19 epidemic declaration on psychological consequences: A study on active Weibo users. International Journal of Environmental Research and Public Health, 17(6), Article e2032. https://doi.org/10 .3390/ijerph17062032

Liu, C. H., Zhang, E., Wong, G. T. F., Hyun, S., \& Hahm, H. C. (2020). Factors associated with depression, anxiety, and PTSD symptomatology during the COVID-19 pandemic: Clinical implications for U.S. young adult mental health. Psychiatry Research, 290, 113172. https://doi.org/10 .1016/j.psychres.2020.113172

Löwe, B., Decker, O., Müller, S., Brähler, E., Schellberg, D., Herzog, W., \& Herzberg, P. Y. (2008). Validation and standardization of the Generalized Anxiety Disorder Screener (GAD-7) in the general population. 
Medical Care, 46(3), 266-274. https://doi.org/10.1097/MLR.0b013e318 160d093

Löwe, B., Kroenke, K., \& Gräfe, K. (2005). Detecting and monitoring depression with a two-item questionnaire (PHQ-2). Journal of Psychosomatic Research, 58(2), 163-171. https://doi.org/10.1016/j.jpsychores .2004 .09 .006

Luchetti, M., Lee, J. H., Aschwanden, D., Sesker, A., Strickhouser, J. E., Terracciano, A., \& Sutin, A. R. (2020). The trajectory of loneliness in response to COVID-19. American Psychologist, 75(7), 897-908. https:// doi.org/10.1037/amp0000690

Ludwig, R. M., Srivastava, S., Berkman, E. T., \& Donnellan, B. (2018). Planfulness: A process-focused construct of individual differences in goal achievement. Collabra. Psychology, 4(1), 28. https://doi.org/10 $.1525 /$ collabra. 136

Lwin, M. O., Lu, J., Sheldenkar, A., Schulz, P. J., Shin, W., Gupta, R., \& Yang, Y. (2020). Global sentiments surrounding the COVID-19 pandemic on Twitter: Analysis of Twitter trends. JMIR Public Health and Surveillance, 6(2), Article e19447. https://doi.org/10.2196/19447

Mak, I. W. C., Chu, C. M., Pan, P. C., Yiu, M. G. C., \& Chan, V. L. (2009). Long-term psychiatric morbidities among SARS survivors. General Hospital Psychiatry, 31(4), 318-326. https://doi.org/10.1016/j .genhosppsych.2009.03.001

Makwana, N. (2019). Disaster and its impact on mental health: A narrative review. Journal of Family Medicine and Primary Care, 8(10), 3090-3095. https://doi.org/10.4103/jfmpc.jfmpc_893_19

Martin, R. C., \& Dahlen, E. R. (2005). Cognitive emotion regulation in the prediction of depression, anxiety, stress, and anger. Personality and Individual Differences, 39(7), 1249-1260. https://doi.org/10.1016/j.paid .2005.06.004

Martínez-Martí, M. L., Theirs, C. I., Pascual, D., \& Corradi, G. (2020). Character strengths predict an increase in mental health and subjective well-being over a one-month period during the COVID-19 pandemic lockdown. Frontiers in Psychology, 11(2790), 584567. https://doi.org/ 10.3389/fpsyg.2020.584567

Matias, T., Dominski, F. H., \& Marks, D. F. (2020). Human needs in COVID-19 isolation. Journal of Health Psychology, 25(7), 871-882. https://doi.org/10.1177/1359105320925149

Mauss, I. B., Levenson, R. W., McCarter, L., Wilhelm, F. H., \& Gross, J. J. (2005, June). The tie that binds? Coherence among emotion experience, behavior, and physiology. Emotion, 5(2), 175-190. https://doi.org/ 10.1037/1528-3542.5.2.175

McCracken, L. M., Badinlou, F., Buhrman, M., \& Brocki, K. C. (2020). Psychological impact of COVID-19 in the Swedish population: Depression, anxiety, and insomnia and their associations to risk and vulnerability factors. European Psychiatry, 63(1), Article e81. https://doi.org/10 $.1192 /$ j.eurpsy.2020.81

McRae, K. (2016). Cognitive emotion regulation: A review of theory and scientific findings. Current Opinion in Behavioral Sciences, 10, 119-124. https://doi.org/10.1016/j.cobeha.2016.06.004

Mennin, D. S., Heimberg, R. G., Turk, C. L., \& Fresco, D. M. (2005). Emotion regulation deficits as a key feature of generalized anxiety disorder: Testing a theoretical model. Behaviour Research and Therapy, 43, 1281-1310. https://doi.org/10.1016/j.brat.2004.08.008

Mennin, D. S., Heimberg, R. G., Turk, C. L., \& Fresco, D. M. (2002). Applying an emotion regulation framework to integrative approaches to generalized anxiety disorder. Clinical Psychology: Science and Practice, 9(1), 85-90. https://doi.org/10.1093/clipsy.9.1.85

Min, J. A., Yu, J. J., Lee, C. U., \& Chae, J. H. (2013). Cognitive emotion regulation strategies contributing to resilience in patients with depression and/or anxiety disorders. Comprehensive Psychiatry, 54(8), 1190-1197. https://doi.org/10.1016/j.comppsych.2013.05.008

Moghanibashi-Mansourieh, A. (2020). Assessing the anxiety level of Iranian general population during COVID-19 outbreak. Asian Journal of Psychiatry, 51, 102076. https://doi.org/10.1016/j.ajp.2020.102076
Mohammed, A., Sheikh, T. L., Poggensee, G., Nguku, P., Olayinka, A., Ohuabunwo, C., \& Eaton, J. (2015). Mental health in emergency response: Lessons from Ebola. The Lancet. Psychiatry, 2(11), 955-957. https://doi.org/10.1016/S2215-0366(15)00451-4

Moors, A., Ellsworth, P. C., Scherer, K. R., \& Frijda, N. H. (2013). Appraisal theories of emotion: State of the art and future development Emotion Review, 5(2), 119-124. https://doi.org/10.1177/17540739124 68165

Moroń, M., \& Biolik-Moroń, M. (2021). Trait emotional intelligence and emotional experiences during the COVID-19 pandemic outbreak in Poland: A daily diary study. Personality and Individual Differences, 168, 110348. https://doi.org/10.1016/j.paid.2020.110348

Motreff, Y., Baubet, T., Pirard, P., Rabet, G., Petitclerc, M., Stene, L. E., Vuillermoz, C., Chauvin, P., \& Vandentorren, S. (2020). Factors associated with PTSD and partial PTSD among first responders following the Paris terror attacks in November 2015. Journal of Psychiatric Research, 121,143-150. https://doi.org/10.1016/j.jpsychires.2019.11.018

Muller, L., \& Spitz, E. (2003). Multidimensional assessment of coping: Validation of the Brief COPE among French population. L'Encéphale, 29(6), 507-518.

Muñoz-Navarro, R., Malonda, E., Llorca-Mestre, A., Cano-Vindel, A., \& Fernández-Berrocal, P. (2021). Worry about COVID-19 contagion and general anxiety: Moderation and mediation effects of cognitive emotion regulation. Journal of Psychiatric Research, 137, 311-318. https://doi .org/10.1016/j.jpsychires.2021.03.004

Naragon-Gainey, K., McMahon, T. P., \& Chacko, T. P. (2017). The structure of common emotion regulation strategies: A meta-analytic examination. Psychological Bulletin, 143(4), 384-427. https://doi.org/10.1037/ bul0000093

Neria, Y., Olfson, M., Gameroff, M. J., Wickramaratne, P., Gross, R., Pilowsky, D. J., Blanco, C., Manetti-Cusa, J., Lantigua, R., Shea, S., \& Weissman, M. M. (2008). The mental health consequences of disasterrelated loss: Findings from primary care one year after the 9/11 terrorist attacks. Psychiatry, 71(4), 339-348. https://doi.org/10.1521/psyc.2008 .71.4.339

North, C. S., \& Pfefferbaum, B. (2013). Mental health response to community disasters: A systematic review. Journal of the American Medical Association, 310(5), 507-518. https://doi.org/10.1001/jama.2013.107799

O'Connor, R. C., Wetherall, K., Cleare, S., McClelland, H., Melson, A. J., Niedzwiedz, C. L., O'Carroll, R. E., O'Connor, D. B., Platt, S., Scowcroft, E., Watson, B., Zortea, T., Ferguson, E., \& Robb, K. A. (2020). Mental health and well-being during the COVID-19 pandemic: Longitudinal analyses of adults in the U.K. COVID-19 Mental Health \& Wellbeing study. The British Journal of Psychiatry, 218, 326-333. https://doi.org/10.1192/bjp.2020.212

Panksepp, J. (1994). The basics of basic emotion. In P. Ekman \& R. J. Davidson (Eds.), The nature of emotion: Fundamental questions (pp. 237-242). Oxford University Press.

Peng, M., Mo, B. R., Liu, Y. S., Xu, M. M., Song, X. R., Liu, L. Y., Fang, Y. Q., Guo, T. Y., Ye, J. Y., Yu, Z. J., Deng, Q. W., \& Zhang, X. Y. (2020). Prevalence, risk factors and clinical correlates of depression in quarantined population during the COVID-19 outbreak. Journal of Affective Disorders, 275, 119-124. https://doi.org/10.1016/j.jad.2020.06 .035

Perneger, T. V. (1998). What's wrong with Bonferroni adjustments. BMJ (Clinical Research Ed.), 316(7139), 1236-1238. https://doi.org/10.1136/ bmj.316.7139.1236

Petzold, M. B., Bendau, A., Plag, J., Pyrkosch, L., Maricic, L. M., Betzler, F., Rogoll, J., Grosse, J., \& Ströhle, A. (2020). Risk, resilience, psychological distress, and anxiety at the beginning of the COVID-19 pandemic in Germany. Brain and Behavior, 10(9), Article e01745. https:// doi.org/10.1002/brb3.1745

Picaza Gorrochategi, M., Eiguren Munitis, A., Dosil Santamaria, M., \& Ozamiz Etxebarria, N. (2020). Stress, anxiety, and depression in people 
aged over 60 in the COVID-19 outbreak in a sample collected in northern Spain. The American Journal of Geriatric Psychiatry, 28(9), 993-998. https://doi.org/10.1016/j.jagp.2020.05.022

Planchuelo-Gómez, Á., Odriozola-González, P., Irurtia, M. J., \& de LuisGarcía, R. (2020). Longitudinal evaluation of the psychological impact of the COVID-19 crisis in Spain. Journal of Affective Disorders, 277, 842-849. https://doi.org/10.1016/j.jad.2020.09.018

Rammstedt, B., Kemper, C. J., Klein, M. C., Beierlein, C., \& Kovaleva, A. (2013). A short scale for assessing the big five dimensions of personality: 10 item Big Five Inventory (BFI-10). Methods, Data, Analyses, 7(2), 233-249.

Rodríguez-Hidalgo, A. J., Pantaleón, Y., Dios, I., \& Falla, D. (2020). Fear of COVID-19, stress, and anxiety in university undergraduate students: A predictive model for depression. Frontiers in Psychology, 11, 591797. https://doi.org/10.3389/fpsyg.2020.591797

Rothman, K. J. (1990). No adjustments are needed for multiple comparisons. Epidemiology, 1(1), 43-46. https://doi.org/10.1097/00001648 $-199001000-00010$

Rudenstine, S., McNeal, K., Schulder, T., Ettman, C. K., Hernandez, M., Gvozdieva, K., \& Galea, S. (2020). Depression and anxiety during the COVID-19 pandemic in an urban, low-income public university sample. Journal of Traumatic Stress. https://doi.org/10.1002/jts.22600

Russell, R. T., Feurer, I. D., Wisawatapnimit, P., Salomon, R. M., \& Pinson, C. W. (2008). The effects of physical quality of life, time, and gender on change in symptoms of anxiety and depression after liver transplantation. Journal of Gastrointestinal Surgery, 12(1), 138-144. https://doi.org/10.1007/s11605-007-0382-X

Saravanan, C., Mahmoud, I., Elshami, W., \& Taha, M. H. (2020 , October). Knowledge, anxiety, fear, and psychological distress about COVID-19 among university students in the United Arab Emirates. Frontiers in Psychiatry, 11, 582189. https://doi.org/10.3389/fpsyt.2020 .582189

Scherer, K. R. (2005). What are emotions? And how can they be measured? Social Sciences Information. Information Sur Les Sciences Sociales, 44(4), 693-727. https://doi.org/10.1177/0539018405058216

Shevlin, M., McBride, O., Murphy, J., Miller, J. G., Hartman, T. K., Levita, L., Mason, L., Martinez, A. P., McKay, R., Stocks, T. V. A., Bennett, K. M., Hyland, P., Karatzias, T., \& Bentall, R. P. (2020, November). Anxiety, depression, traumatic stress and COVID-19-related anxiety in the U.K. general population during the COVID-19 pandemic. Bjpsych Open, 6(6), Article e125. https://doi.org/10.1192/bjo.2020.109

Shigemura, J., Terayama, T., Kurosawa, M., Kobayashi, Y., Toda, H., Nagamine, M., \& Yoshino, A. (2021). Mental health consequences for survivors of the 2011 Fukushima nuclear disaster: A systematic review. Pt. 1: psychological consequences. CNS Spectrums, 26(1), 14-29. https://doi.org/10.1017/S1092852920000164

Sica, C., Novara, C., Dorz, S., \& Sanavio, E. (1997). Coping strategies: Evidence for cross-cultural differences? A preliminary study with the Italian version of coping orientations to problems experienced (COPE Personality and Individual Differences, 23(6), 1025-1029. https://doi .org/10.1016/S0191-8869(97)00112-8

Sighinolfi, C., Pala, A. N., Chiri, L. R., Marchetti, I., \& Sica, C. (2010). Difficulties in Emotion Regulation Scale (DERS): Traduzione e adattamento Italiano. Psicoterapia Cognitiva e Comportamentale, 16(2), 141-170.

Smith, C. A., \& Ellsworth, P. C. (1985). Patterns of cognitive appraisal in emotion. Journal of Personality and Social Psychology, 48(4), 813-838. https://doi.org/10.1037/0022-3514.48.4.813

Smith, L., Jacob, L., Yakkundi, A., McDermott, D., Armstrong, N. C., Barnett, Y., Lopez-Sanchez, G. F., Martin, S., Butler, L., \& Tully, M. A. (2020). Correlates of symptoms of anxiety and depression and mental wellbeing associated with COVID-19: A cross-sectional study of U.K.- based respondents. Psychiatry Research, 291, 113138. https://doi.org/10 .1016/j.psychres.2020.113138

Spitzer, R. L., Kroenke, K., Williams, J. B., \& Löwe, B. (2006). A brief measure for assessing generalized anxiety disorder: The GAD-7. Archives of Internal Medicine, 166(10), 1092-1097. https://doi.org/10 $.1001 /$ archinte.166.10.1092

Sweeney, M. (2020, September). Counseling clients during New York City's COVID-19 pandemic: Observations on fundamental elements of emotions management. Irish Journal of Psychological Medicine, 37(3), 212-213. https://doi.org/10.1017/ipm.2020.42

Tang, F., Liang, J., Zhang, H., Kelifa, M. M., He, Q. Q., \& Wang, P. G. (2020). COVID-19 related depression and anxiety among quarantined respondents. Psychology \& Health. Advance online publication. https:// doi.org/10.1080/08870446.2020.1782410

Trougakos, J. P., Chawla, N., \& McCarthy, J. M. (2020). Working in a pandemic: Exploring the impact of COVID-19 health anxiety on work, family, and health outcomes. Journal of Applied Psychology, 105(11), 1234-1245. https://doi.org/10.1037/ap10000739

Tugade, M. M., Fredrickson, B. L., \& Barrett, L. F. (2004). Psychological resilience and positive emotional granularity: Examining the benefits of positive emotions on coping and health. Journal of Personality, 72(6), 1161-1190. https://doi.org/10.1111/j.1467-6494.2004.00294.x

Tull, M. T., \& Roemer, L. (2007). Emotion regulation difficulties associated with the experience of uncued panic attacks: Evidence of experiential avoidance, emotional nonacceptance, and decreased emotional clarity. Behavior Therapy, 38(4), 378-391. https://doi.org/10.1016/j .beth.2006.10.006

Van Bortel, T., Basnayake, A., Wurie, F., Jambai, M., Koroma, A. S., Muana, A. T., Hann, K., Eaton, J., Martin, S., \& Nellums, L. B. (2016). Psychosocial effects of an Ebola outbreak at individual, community and international levels. Bulletin of the World Health Organization, 94(3), 210-214. https://doi.org/10.2471/BLT.15.158543

Watson, D., Clark, L. A., \& Tellegen, A. (1988). Development and validation of brief measures of positive and negative affect: The PANAS scales. Journal of Personality and Social Psychology, 54(6), 1063-1070. https://doi.org/10.1037/0022-3514.54.6.1063

Wheaton, M. G., Abramowitz, J. S., Berman, N. C., Fabricant, L. E., \& Olatunji, B. O. (2012). Psychological predictors of anxiety in response to the H1N1 (Swine Flu) pandemic. Cognitive Therapy and Research, 36(3), 210-218. https://doi.org/10.1007/s10608-011-9353-3

Xiong, J. Q., Lipsitz, O., Nasri, F., Lui, L. M. W., Gill, H., Phan, L., ChenLi, D., Iacobucci, M., Ho, R., Majeed, A., \& McIntyre, R. S. (2020). Impact of COVID-19 pandemic on mental health in the general population: A systematic review. Journal of Affective Disorders, 277, 55-64. https://doi.org/10.1016/j.jad.2020.08.001

Yip, P. S. F., Cheung, Y. T., Chau, P. H., \& Law, Y. W. (2010).The impact of epidemic outbreak: The case of severe acute respiratory syndrome (SARS) and suicide among older adults in Hong Kong. Crisis: The Journal of Crisis Intervention and Suicide Prevention, 31(2), 86-92. https:// doi.org/10.1027/0227-5910/a000015

Zacher, H., \& Rudolph, C. W. (2021). Individual differences and changes in subjective wellbeing during the early stages of the COVID-19 pandemic American Psychologist, 76(1), 50-62. https://doi.org/10.1037/amp0000702

Zlomke, K. R., \& Hahn, K. S. (2010). Cognitive emotion regulation strategies: Gender differences and associations to worry. Personality and Individual Differences, 48(4), 408-413. https://doi.org/10.1016/j paid.2009.11.007

Received December 24, 2020

Revision received August 11, 2021 Accepted August 12, 2021 